\title{
Protein change in plant evolution: tracing one thread connecting molecular and phenotypic diversity
}

\author{
Madelaine E. Bartlett and Clinton J. Whipple*
}

Biology Department, Brigham Young University, Provo, UT, USA

Edited by:

Jill Christine Preston, University of

Vermont, USA

\section{Reviewed by:}

Stephan Wenkel, University of

Tuebingen, Germany

Elena M. Kramer, Harvard University, USA

Alma Pineyro-Nelson, University of California Berkeley, USA

\section{${ }^{*}$ Correspondence:}

Clinton J. Whipple, Biology Department, Brigham Young University, 401 WIDB, Provo, UT 84602, USA

e-mail:whipple@byu.edu
Proteins change over the course of evolutionary time. New protein-coding genes and gene families emerge and diversify, ultimately affecting an organism's phenotype and interactions with its environment. Here we survey the range of structural protein change observed in plants and review the role these changes have had in the evolution of plant form and function. Verified examples tying evolutionary change in protein structure to phenotypic change remain scarce. We will review the existing examples, as well as draw from investigations into domestication, and quantitative trait locus (QTL) cloning studies searching for the molecular underpinnings of natural variation. The evolutionary significance of many cloned OTL has not been assessed, but all the examples identified so far have begun to reveal the extent of protein structural diversity tolerated in natural systems. This molecular (and phenotypic) diversity could come to represent part of natural selection's source material in the adaptive evolution of novel traits. Protein structure and function can change in many distinct ways, but the changes we identified in studies of natural diversity and protein evolution were predicted to fall primarily into one of six categories: altered active and binding sites; altered protein-protein interactions; altered domain content; altered activity as an activator or repressor; altered protein stability; and hypomorphic and hypermorphic alleles. There was also variability in the evolutionary scale at which particular changes were observed. Some changes were detected at both micro- and macroevolutionary timescales, while others were observed primarily at deep or shallow phylogenetic levels. This variation might be used to determine the trajectory of future investigations in structural molecular evolution.

Keywords: molecular evolution, structural mutations, protein evolution, coding vs. non-coding changes, plant evo-devo, genotype to phenotype map

\section{INTRODUCTION}

In the study of the molecular changes underlying adaptive evolution, there is debate as to whether regulatory or structural changes are of greater importance. Regulatory changes, especially those affecting where and when a transcriptional regulator is expressed, are thought to predominate. Structural changes are thought to have a higher degree of negative pleiotropy, and are probably not tolerated to the same degree as regulatory changes (Carroll, 2000, 2005, 2008; Stern, 2000). Despite this prevailing view, structural changes have been shown to have had a noteworthy role in the evolution of some key adaptive traits (Hoekstra and Coyne, 2007). In the evolution of plant form and function in particular, examples of both regulatory (Arnaud et al., 2011) and structural (Airoldi et al., 2010) changes exist. With time and more data, the argument may be resolved, but the point that every trait is different may be key (Wessinger and Rausher, 2012). In all likelihood, in most cases there is no single quantitative trait nucleotide (QTN), but rather a collection of myriad small changes, both regulatory and structural, that have contributed to the evolution of a novel phenotype (Rockman, 2012).

Regardless of which class of changes predominates, both regulatory and structural mutations have happened through the course of evolution. We have chosen to review those cases where structural mutations have had demonstrably functional consequences. Interpreting a mutation as either regulatory or structural is not always straightforward. We use the definition proposed by Hoekstra and Coyne (2007), with some modifications. They propose that mutations that occur in the coding sequences of genes are structural, and all other mutations, including those that occur in introns, are regulatory. This definition includes nonsense null mutations, altered miRNA-binding sites, and silent mutations affecting transcription and translation dynamics as "structural" (Hoekstra and Coyne, 2007). We prefer a more narrow definition of "structural mutation," and include only those examples where amino acid sequence is changed and protein function is not completely lost. This circumscription of structural mutations thus includes mostly missense mutations, but also insertions and deletions, frameshifts, and premature stop codons that produce proteins with altered functions. We have chosen this definition out of expediency. Compelling arguments exist for putting all excluded mutations (e.g., miRNA-binding site mutations) back into the set of structural mutations, and then for taking them right back out again. For the purpose of investigating the evolution of protein function, we feel that our narrow definition best frames the discussion.

Our review focuses on those cases where protein function has been altered, in turn altering some aspect of phenotype. It is 
important to highlight that many of the phenotypes we discuss may or may not be adaptive, but that is not the focus of this review. It is not trivial to unambiguously determine the molecular cause of a phenotypic adaptation, or even to confirm some phenotype as adaptive (Barrett and Hoekstra, 2011). Moreover, there are few studies that have explicitly investigated the quantitative trait loci (QTL) underlying natural variation in an evolutionary framework, and as a consequence it is hard to determine their adaptive significance. A more widespread genotype might hint at some adaptive value, but for many of the examples we cite the responsible protein change is only found in a single accession where it may be deleterious and/or of short duration. These isolated QTL are not inherently less interesting, however, because they reveal the scope of molecular diversity to be found in natural environments, diversity that selection may ultimately act upon.

Another important preliminary consideration is that protein diversification through deep time can only be discussed in a framework of gene birth. In plants in particular, and in eukaryotes in general, a major source of new genes is gene duplication. Most gene families have expanded considerably through gene duplication and divergence, and often these expansions show lineage-specific patterns (Flagel and Wendel, 2009). The new gene duplicates are thought to have one of three fates. Formally, duplicate genes may divide up the functions of the progenitor gene between them (subfunctionalization), one of the duplicates may gain an entirely new function (neofunctionalization), or one of the duplicates may decay into a non-functional pseudogene (Ohno, 1970; Lynch et al., 2001). These categories are often difficult to assign, but where they are relevant, most of the examples we will discuss are of neofunctionalization.

In our review of the literature, we found that functional protein changes, the result of underlying structural mutations, fell into six broad, non-mutually exclusive categories. We have divided up our discussion according to these categories: (I) altered active or binding sites; (II) altered protein-protein interactions; (III) altered domain content; (IV) altered activity as a transcriptional activator or repressor; (V) altered protein stability; or (VI) hypomorphic and hypermorphic alleles (Figure $\mathbf{1}$ and Table $\mathbf{1}$ ).

\section{ALTERED ACTIVE AND BINDING SITES}

Amino acid replacement in the active sites of enzymes, or the DNA-binding sites of transcription factors, is perhaps the most easily understood mechanism of protein evolution. Changes to the core functional domain of a protein, either through gradual replacement of many amino acids over the course of time (Zhao et al., 2008), or through the replacement of a few key residues (Greenhagen et al., 2006; O'Maille et al., 2008), has the potential to generate novel protein function. Active and binding site changes also have the greatest potential to be deleterious if they destroy a protein's primary function (Carroll, 2008). Despite this potential for negative effects, numerous examples (outlined below) have been uncovered where active and binding site evolution has been tolerated and led to neofunctionalization.

\section{SECONDARY METABOLITES IN DEFENSE}

Plants are remarkable for their secondary metabolite chemistry: they possess a diversity of chemical compounds, often involved in defense (Dixon, 2001). Gene duplication followed by neofunctionalization is a novelty-generating mechanism observed frequently in the evolution of enzymes and secondary metabolites. Gene duplication followed by active site evolution has been described in the synthesis of the arabidopyrones (Arabidopsis-specific compounds; Weng etal., 2012); glucosinolates in the Arabidopsis relative Boechera (Prasad et al., 2012); and pyrrolizidine alkaloids in the Convolvulaceae and the Asteraceae (Anke et al., 2004; Reimann et al., 2004). Both in the evolution of novel glucosinolateproducing enzymes in Boechera (Prasad et al., 2012), and in the evolution of pyrrolizidine alkaloid production in the Convolvulaceae (Kaltenegger et al., 2013), positive selection acting on active site amino acid residues was detected. The positively selected residues were assayed for function, and found to indeed alter enzyme function in predictable ways (Prasad et al., 2012; Kaltenegger et al., 2013). This pattern of gene duplication, positive selection, and neofunctionalization has been proposed as a mechanism for glucosinolate biosynthesis evolution in the Brassicaceae (Benderoth et al., 2006), and appears to be relevant for a broader spectrum of secondary metabolite evolution.

A second theme observed in the evolution of novel enzymes is that of a promiscuous enzyme becoming more specialized through the course of evolution. In both pyrrolizidine alkaloid and arabidopyrone synthesis, the enzyme maintaining ancestral function shows weak activity toward the substrate used by the neofunctionalized enzyme (Weng et al., 2012; Kaltenegger et al., 2013). In these cases, which may be fairly prevalent, the catalytic activity of the progenitor enzyme may be considered a molecular exaptation. An exaptation, as defined by Gould and Vrba (1982), is a feature coopted for some current function following an origin for a different function, or no function at all. Promiscuous catalytic activity of an enzyme may serve as an exaptation in the evolution of new enzyme functions after gene duplication (O'Brien and Herschlag, 1999; Aharoni et al., 2004). This may also still be considered neofunctionalization, depending on the definition of function used. If an evolutionary definition of function is used - an enzyme's function is the function it was selected for - then the increased specialization is indeed neofunctionalization. If, instead, we choose a purely mechanical definition - a promiscuous enzyme functions to produce a range of products - then exaptation, but not neofunctionalization, would be better applied. In the case of biochemical enzymes, many neofunctionalization events may be exaptations, but not all neofunctionalization events are because of exaptation.

\section{HERBICIDE RESISTANCE}

Herbicide resistance, both naturally and experimentally derived, is often the result of structural changes, particularly in the active sites of enzymes. The possible shifts to resistance in an herbicidesensitive protein is dependent on where a particular herbicide binds. If an herbicide binds within an enzyme's catalytic site, there are relatively few amino acid changes that can confer resistance, while still maintaining catalytic activity. If an herbicide binds outside of an enzyme's catalytic site, a larger spectrum of changes can confer resistance while still maintaining enzyme function. Because herbicide treatment represents extremely strong selective pressure, applied in agricultural settings worldwide, and because both sets of tolerated amino acid changes are relatively small, the evolution 
A

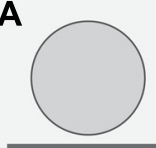

I Altered active or binding site

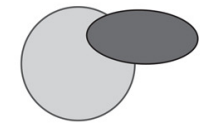

II Altered protein-protein interactions

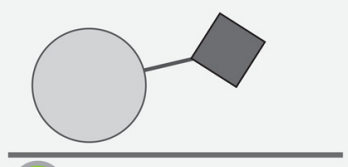

III Altered domain content
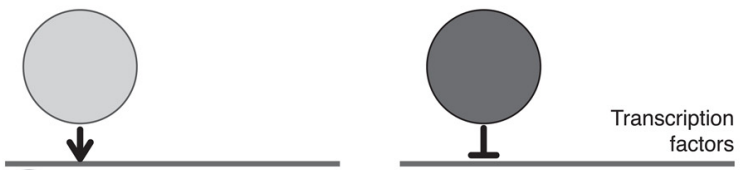

IV Altered activity as an activator or repressor

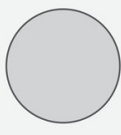

v Altered stability

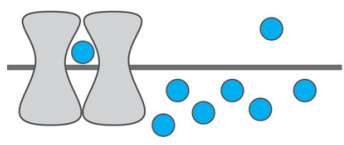

VI Hypomorphic and hypermorphic alleles
Light-signaling proteins

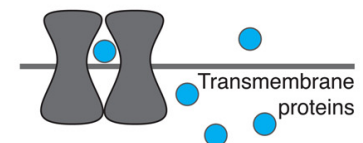

FIGURE 1 | Structural changes observed in plant phenotypic variation and evolution. (A) The six classes of structural change identified. The dominant family of proteins identified as being affected by each class of change is noted. In I-IV the gray line represents DNA, in VI it represents
B

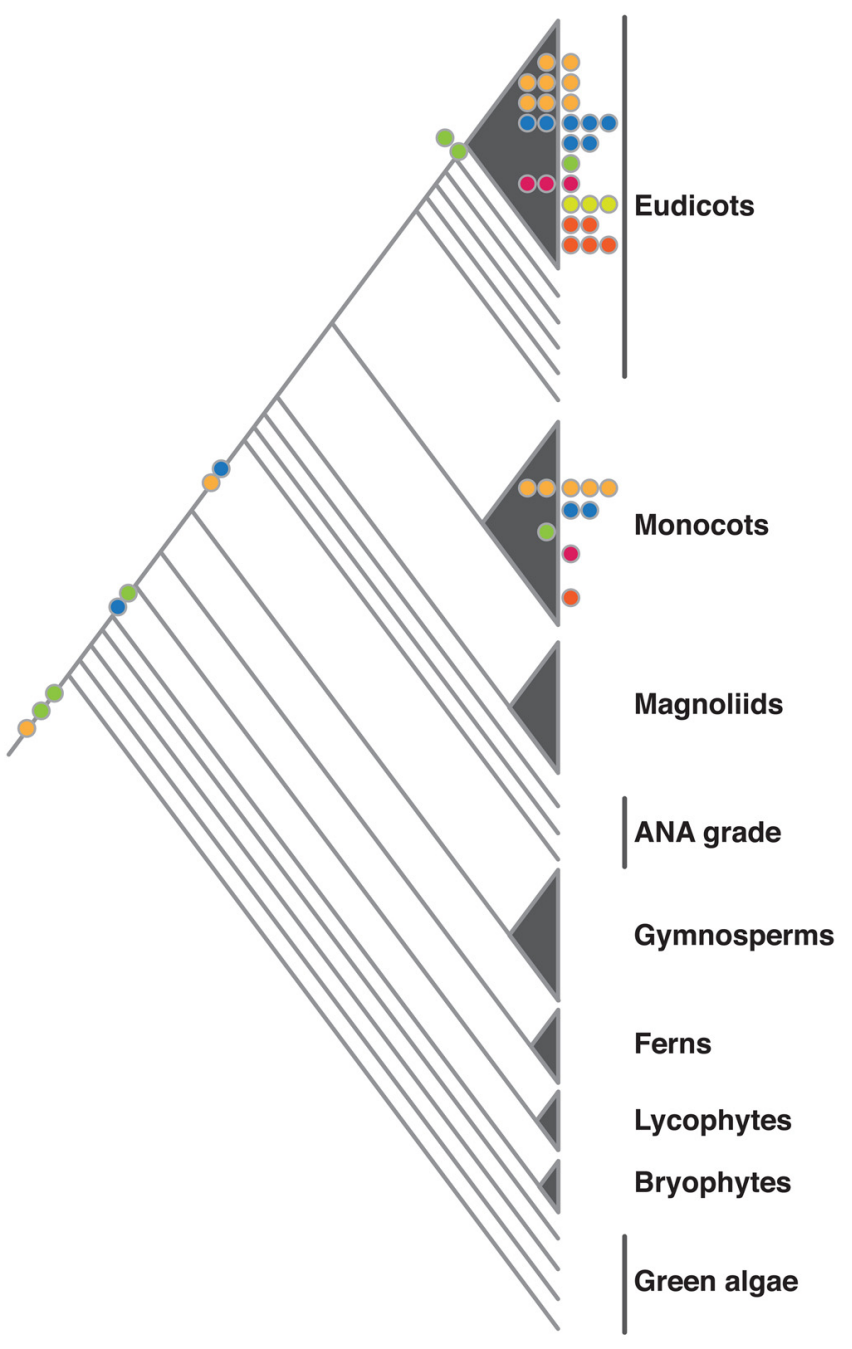

the cell membrane. (B) The approximate phylogenetic placement of described structural changes. Colored circles on branches or within clades represent change at the macroevolutionary level. Colored circles at tips represent microevolutionary changes (color coding as in $\mathbf{A}$ ). of herbicide resistance is a story of molecular convergence. For example, a single amino acid change that confers triazine herbicide resistance in a key photosystem II gene, $p s b A(\mathrm{~S} 264 \mathrm{G})$, has evolved independently at least 68 times worldwide. Similarly, 22 amino acid replacements at seven sites in the enzyme acetohydroxyacid synthase (AHAS) have been identified in herbicide-resistant weeds (reviewed in Powles and Yu, 2010). In a final example of molecular convergence, the same herbicide resistance-conferring mutation (T239I) has arisen separately in the $\alpha$-tubulin genes of the grasses Eleusine indica and Setaria viridis (Anthony et al., 1998; Yamamoto et al., 1998).

\section{FLOWER COLOR EVOLUTION}

Flower color evolution is another domain where structural changes in enzymes, along with regulatory changes and enzyme inactivations, have been shown to be important (Wessinger and
Rausher, 2012). In Iochroma (Solanaceae) a color change from blue (ancestral) to red (derived) occurred because of three changes: inactivation of one enzyme, downregulation of a second by a distinct locus, and altered functional specificity of a third (Dfr; Smith and Rausher, 2011). It remains unclear which changes occurred first, and were ultimately responsible for the color shift, but it is clear that changes in Dfr specificity occurred both before and after the emergence of the red-flowered ancestor. The five amino acids that differ between the red-flowered and blue-flowered ancestral proteins evolved under positive selection. Ancestral sequence estimation, coupled to site-directed mutagenesis and functional assays revealed that each amino acid change, when it occurs in a specific protein sequence background, confers progressively more specificity for the red color precursor. These results suggest that each of the amino acid changes in Dfr may have been adaptive (Smith et al., 2013). 


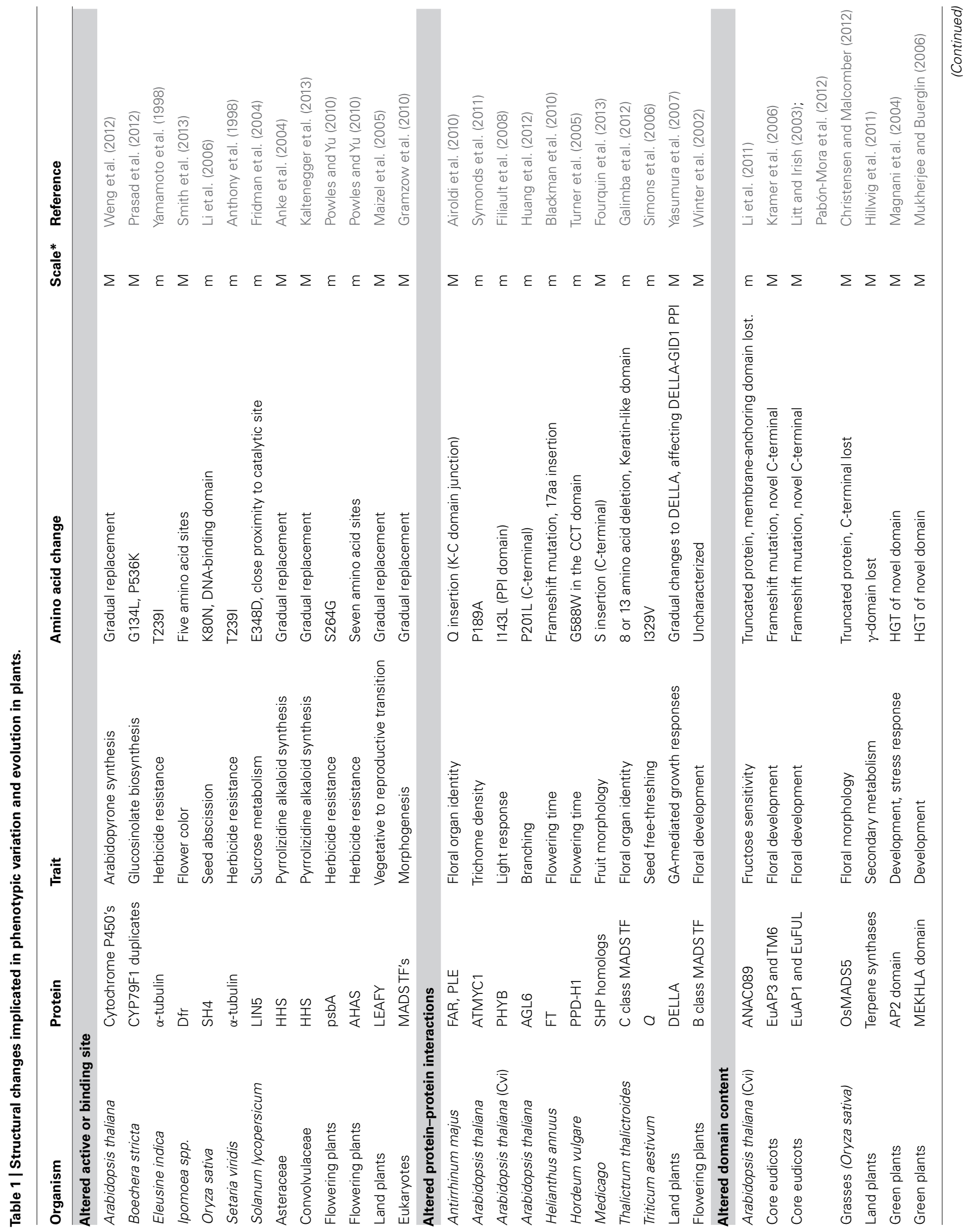




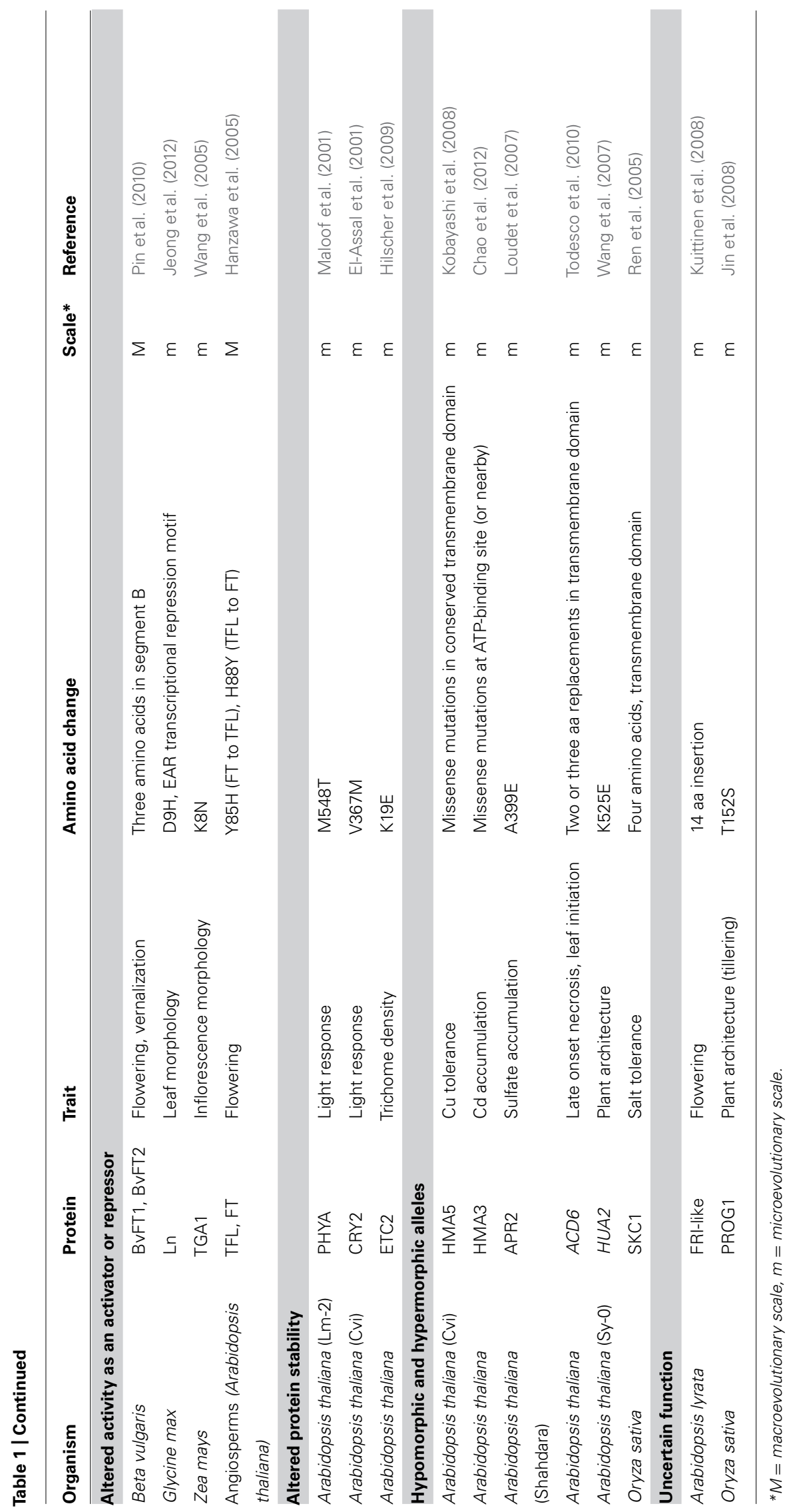




\section{DNA-BINDING SITE EVOLUTION}

Regulatory changes are often considered more prevalent in the evolution of transcription factor function, and hence in the evolution of morphology. However, there is evidence that binding (active) site evolution is of some importance in the evolution of the LEAFY (LFY) and MADS box transcription factors. The $A$. thaliana protein LFY, like its orthologs in other flowering plants, is a floral integrator and a master regulator of floral organ identity (Moyroud et al., 2010). In the moss Physcomitrella patens, however, the two LFY genes control the first zygotic cell division and numerous aspects of sporophyte development, not the vegetative to reproductive transition in the sporophyte (Tanahashi et al., 2005). In Ceratopteris, a fern, the expression patterns of LFY homologs and other MADS box genes are not overlapping, suggesting that LFY does not induce MADS box gene expression, as it does in the flowering plants (Himi et al., 2001). Changes in the DNA-binding domain appear to have been important in this altered functional specificity of LFY across the evolutionary history of land plants. Heterologous expression studies, domain swaps, and site-directed mutagenesis experiments suggest that gradual amino acid replacement in the DNA-binding domain, through the course of plant evolution, may have been of some importance in the evolution of altered LFY function (Maizel et al., 2005).

The MADS box genes are found in almost all eukaryotic genomes, and have expanded considerably in plant genomes in particular. Plant MADS box genes have key roles in many morphogenetic processes, including flowering, floral development, and fruit development. Careful and exhaustive database searches and phylogenetic analyses have revealed that the MADS box genes of eukaryotes may have evolved from a gene encoding a topoisomerase subunit (TopoIIA subunit A). DNA topoisomerases, like TopoIIA, have central roles in DNA replication, transcription, recombination, and chromosome segregation. Gradual changes in the DNA-binding domain may have eventually led to the DNAbinding specificity for CArG boxes observed in MADS box proteins (Gramzow et al., 2010).

A single amino acid replacement $(\mathrm{K} 80 \mathrm{~N})$ in the MYB domain transcription factor SHATTERING4 (SH4) is responsible for the non-shattering phenotype characteristic of cultivated rice (Li et al., 2006; Zhu et al., 2012). In wild rice species, the seeds abscise from the inflorescence axis (shattering) because of the formation of an abscission zone. In cultivated rice, seeds are retained on the inflorescence axis and the abscission zone is reduced, allowing for easier harvest. $\mathrm{K} 80 \mathrm{~N}$ is in the DNA-binding domain of sh4 and probably undermines or changes (but not abolishes) protein function, thus interrupting abscission layer formation (Li et al., 2006).

Structural active site changes may well be tolerated at a higher frequency in biosynthetic enzymes, and lead to novel phenotypes more often than analogous changes in transcription factors, but we see no particular reason to consider the evolution of transcription factors and the evolution of biochemical enzymes as two fundamentally distinct processes. We suspect that one of the recurrent themes identified in enzyme evolution - gene duplication followed by neofunctionalization - may rather become a more general theme in protein evolution. Gradual binding site evolution of transcription factors, as demonstrated in LFY and suggested in the MADS box proteins, may be more widespread. Although DNA-binding domains are often deeply conserved in gene families, it remains conceivable that the DNA-binding profile of a transcription factor may diverge following a gene duplication event. It is fairly laborious to identify transcription factor binding sites, even in model organisms. More sequenced genomes, however, along with new techniques such as chromatin immunoprecipitation coupled to next generation sequencing (ChIP-Seq) may allow us to uncover more examples of structural transcription factor evolution. ChIP-Seq has the potential to reveal altered DNA-binding profiles through time, whether this is because of altered binding sites, altered protein-protein interactions (PPIs), or other mechanisms. This is not to discount the demonstrated importance of changes in transcription factor gene expression in morphological evolution (Arnaud et al., 2011), but only to highlight the potential importance of structural and regulatory changes occurring together through deep time.

Molecular convergence may also become a more general theme in protein evolution (Gherardini et al., 2007). As with biosynthetic enzymes, a protein with DNA-binding activity has a finite genotypic space to explore in adopting some new function (binding a new DNA motif, for example) (Wagner, 2011). Consequently, the subset of changes that can occur at key residues is relatively small. Further examples may reveal recurrent changes in homologous protein domains not just in biosynthetic enzymes and herbicide-targeted proteins, but also in transcription factors.

\section{ALTERED PROTEIN-PROTEIN INTERACTIONS}

Protein-protein interactions are of prime importance in plant development. There are many examples of particular interactions regulating key developmental and physiological processes (e.g., Riechmann et al., 1996a; Kim et al., 1997; Cui et al., 2007). Altered PPIs may be one way to generate functional diversity without negatively affecting core protein function. The DNA-binding domain of a protein may stay intact, but an interaction domain may change to interact with a new partner, perhaps expressed in a discrete domain. In this way novel functions can emerge, while the protein's original functions are preserved (Lynch and Wagner, 2008). Despite this compelling argument for investigating PPI evolution, and despite their integral role in development, few studies have tackled PPIs in an evolutionary framework.

One interaction that has been studied in an evolutionary context occurs between the gibberellin phytohormones (GA), GID1-like proteins (GLP1), and the DELLA transcriptional repressors. In A. thaliana DELLA proteins, as part of GLP1-GA-DELLA complexes, are polyubiquitinated and recruited to the $26 \mathrm{~S}$ proteasome for destruction, releasing DELLA targets from repression (reviewed in Sun, 2011). The GLP1-GA-DELLA interaction is deeply conserved in angiosperms (Sun, 2011), and appears to have been acquired gradually through the course of land plant evolution (Yasumura etal., 2007). The results of mutant analyses and heterologous transformation experiments suggest that DELLA's acquired their characteristic growth-repressive function after the divergence of the lycophytes from the rest of the land plants, perhaps through cis-regulatory changes. The GA-stimulated GLP1-DELLA interaction appears to have arisen after the divergence of the bryophytes from the remainder of the 
land plants, probably through structural alterations to DELLA proteins. Thus DELLA protein changes that facilitate the GLP1DELLA interaction, together with the evolution of an altered GA response, allowed for the emergence of the GLP1-GA-DELLA module characteristic of flowering plants (Yasumura et al., 2007).

In the study of plant development, the network of interactions between the $\mathrm{ABC}(\mathrm{E}) \mathrm{MADS}$ box proteins has been extensively investigated. The $\mathrm{ABC}(\mathrm{E})$ class MADS box genes, and the single non-MADS A class gene AP2 (APETALA2), control floral organ identity in a combinatorial manner. In Arabidopsis and Antirrhinum the A class genes control sepal identity. The A and B class genes together control petal identity, $\mathrm{B}$ and $\mathrm{C}$ class genes together confer stamen identity, and the $\mathrm{C}$ class genes control carpel identity (Coen and Meyerowitz, 1991). The E class genes are needed in all four whorls of the flower for proper organ identity specification (Pelaz et al., 2000; Honma and Goto, 2001). The ABC(E) MADS box proteins are known to dimerize, but probably function as part of tetramers ("floral quartets"). These proteins have four domains: the DNA-binding MADS domain, an Intervening domain (I), a keratin-like coiled coil (K), and a disordered Cterminal domain. The I, K, and C-domains have been implicated in mediating PPIs amongst MADS box proteins (reviewed in Immink et al., 2010).

There are a few examples where novel mutant phenotypes are probably caused by disrupted PPIs of MADS box transcription factors. The fast neutron induced seirena mutant of the California poppy, Eschscholzia californica (Ranunculaceae), shows a $\mathrm{B}$ class mutant phenotype, and may result from compromised interactions between the B class, $\mathrm{C}$ class, and $\mathrm{E}$ class MADS box proteins. Site-directed mutagenesis experiments revealed that the B-C-E interaction in Eschscholzia may be mediated by the PISTILLATA (PI) motif, missing from sei-1 mutant protein (Lange et al., 2013). The PI motif is conserved, but not universally present, in PI homologs. Although the PI motif may well have a role in MADS box complex formation wherever it is found, distinct interaction motifs may have evolved convergently in lineages where the PI motif is missing or altered, but higher order complexes still form (Lange et al., 2013). The double-flowered mutant phenotype of an ornamental cultivar of Thalictrum thalictroides (Ranunculaceae) may also be the result of disrupted PPIs between $\mathrm{C}$ and $\mathrm{E}$ class MADS box proteins (Galimba et al., 2012).

APETALA3 (AP3)-like and PI-like genes comprise the two main lineages of $\mathrm{B}$ class MADS box genes. In all core eudicots investigated thus far, B class proteins bind DNA as obligate heterodimers: AP3-like proteins cannot bind DNA without PIlike proteins and vice-versa (Riechmann etal., 1996a,b). The AP3-PI heterodimer in Arabidopsis goes on to autoregulate late PI and AP3 expression (Honma and Goto, 2000). This obligate heterodimer relationship is uncommon in the large MADS box gene family (Riechmann etal., 1996a), and obligate heterodimerization coupled with autoregulation is a rare, if not unique regulatory mechanism. All angiosperms investigated thus far have at least one AP3-like and one PI-like gene, and AP3like and PI-like proteins bind DNA as obligate heterodimers in distantly related angiosperms, including the grass Zea mays (Vandenbussche et al., 2004; Whipple et al., 2004; Drea et al., 2007; Kramer et al., 2007). The only characterized B class proteins isolated from a gymnosperm thus far (the Gnetalean Gnetum gnemon) bind DNA as homodimers (Winter et al., 2002; Wang et al., 2010). These data, taken together, suggested that the obligate heterodimerization relationship evolved from a homodimerizing ancestor shortly after the duplication event that led to the AP3 and PI gene lineages, and prior to the diversification of the angiosperms. However, PI homologs from Lilium were found to be capable of homodimerizing and heterodimerizing (Winter et al., 2002), but with no other data points, it was unclear whether this was an autapomorphy or indicative of a broader evolutionary trend. The single PI-like protein (J-PI) in Joinvillea, a close grass relative, can homodimerize (Whipple and Schmidt, 2006). PI-like homodimerization has also been observed in Chloranthus (Chloranthaceae; Li et al., 2005) and Eschscholzia (Lange et al., 2013). Together with the data from Lilium, these data imply the intriguing convergent evolution of obligate heterodimerization both in the monocots and in the lineage leading to the core eudicots. What remains to be deciphered is why obligate $\mathrm{B}$ class heterodimerization evolved at least twice. What, if any, is the functional difference between B class homodimers and heterodimers? One hypothesis suggests that the convergent evolution of obligate AP3-PI interaction is not the result of drift, but rather because the AP3-PI heterodimer confers a selective advantage: a robust switch in floral development (Lenser et al., 2009). It must be stated that all investigations into B class homo- vs. heterodimerization have been conducted in vitro. There is no evidence as of yet that PI-like homodimers function in planta.

The C class genes (PLENA and FARINELLI) of Antirrhinum have subfunctionalized, in part because of shifting PPIs. PLENA controls both male and female organ identity (stamens and carpels), while FARINELLI confers only male organ identity, both in $A$. majus and when overexpressed in A. thaliana flowers (Davies et al., 1999; Causier et al., 2005; Airoldi et al., 2010). When ectopically expressed, PLE, like AG, is capable of specifying both male (stamen) and female (carpel) organ identity, but FAR confers only stamen identity. This functional divergence has been traced to a single glutamine insertion in FAR, the result of an altered splice site. This amino acid insertion affects PPIs with the E class SEPALLATA (SEP) proteins: FAR can only interact with SEP3, while AG can interact with SEP1, 2, and 3. This change in PPIs, overlaid on SEP homolog expression patterns, has resulted in the subfunctionalization of FAR and PLE. Structural and regulatory changes have acted in concert to effect functional differentiation (Airoldi et al., 2010). In the genus Medicago (Fabaceae), a major difference in fruit morphology is correlated with a similar single amino acid insertion into SHATTERPROOF (SHP)-like MADS box proteins. Rather than disrupting PPIs, however, the amino acid insertion may strengthen the interaction between Medicago SHP and SEP3 homologs (Fourquin et al., 2013).

Outside of the MADS box genes, there is evidence that PPIs affect natural variation in altered trichome density (Symonds et al., 2011) and light response in A. thaliana (Filiault et al., 2008), domestication traits in wheat (Simons et al., 2006), and flowering time in barley (Turner et al., 2005). Trichome density, in particular, changes in response to herbivore pressure, and has a fitness effect (Mauricio, 1998). The bHLH transcription factor ATMYC1 was found to underlie a QTL for trichome density in four separate 
A. thaliana mapping populations. A single amino acid change (P189A) was sufficient to abolish binding of atmyc1 to TTG (TRANSPARENT TESTA GLABRA) and GL1 (GLABROUS1) in yeast two hybrid assays (Symonds et al., 2011). Both TTG and GL1 are essential for trichome initiation in A. thaliana (reviewed in Balkunde etal., 2010). Presumably it is this altered interface with the trichome initiation pathway that results in reduced trichome initiation in plants with the Ler atmycl allele. In a cautionary tale for evolutionary biologists, positive selection acting on the ATMYC1 coding sequence was detected, but the region under selection was downstream of the trichome-reducing P189A substitution (Symonds et al., 2011).

\section{COMPETITIVE INHIBITION AND DOMINANT NEGATIVES}

Competitive inhibition of transcription factors by similar, but truncated, proteins represents one special PPI that has repeatedly surfaced as a regulatory mechanism (Staudt and Wenkel, 2010; Seo et al., 2011a). For example, the HD-ZIPIII transcription factor REVOLUTA, a key regulator of vegetative development (reviewed in Floyd et al., 2006), is negatively regulated by the LITTLE ZIPPER (ZPR) proteins. HD-ZIPIII transcription factors consist of four domains: a DNA-binding homeodomain, a leucine zipper domain, a START domain predicted to bind small hydrophobic molecules, and a MEKHLA domain (discussed below). All of the HD-ZIPIII proteins bind DNA as dimers. One class of genes that is upregulated by REV in particular is the $Z P R$ genes. In contrast to the HD-ZIPIII proteins, the only recognizable domain in the ZPR proteins is the leucine zipper domain (Wenkel et al., 2007; Kim et al., 2008). The ZPR proteins bind REV in vitro, and inhibit DNA binding by REV. The ZPR overexpression phenotypes resemble those seen when HD-ZIPIII function is reduced. These data suggest a negative feedback loop, where the HD-ZIPIII proteins upregulate $Z P R$ expression and the ZPR proteins repress HD-ZIPIII genes by sequestering them in inactive heterodimers. $Z P R$ genes have been found in Arabidopsis, maize, and rice, so this form of gene regulation may be relatively ancient in the flowering plants (Wenkel et al., 2007).

The form of competitive inhibition demonstrated in the HDZIPIII/ZPR system is evident in a number of other transcription factor families: IDD14 in starch accumulation (Seo et al., 2011b), ZHD5 and MIF in floral and leaf development (Hong et al., 2011), Aux/IAA and ARF proteins in auxin response (Ulmasov et al., 1997; Vernoux etal., 2011), MEINOX and BELL proteins in leaf development (Magnani and Hake, 2008), and the MYB proteins DIVARICATA and RADIALIS in establishing floral symmetry (Corley etal., 2005; Raimundo et al., 2013). The smaller, competitive inhibitor proteins have been termed microProteins or short interfering peptides (siPEPs; Staudt and Wenkel, 2010; Seo et al., 2011a). Very few of these systems have been investigated in an evolutionary context, so it remains unclear whether the siPEPs have arisen because of convergent evolution, or whether they share a common ancestor with their competitors and have undergone domain loss. The second scenario, common ancestry and domain loss, seems more likely given the widespread occurrence of domain loss in gene family evolution (Bornberg-Bauer et al., 2010). In the case of IDD14, the competitive inhibitor is the result of an alternative splicing event, suggesting that there may be many more examples of competitive inhibition lurking in plant genomes (Staudt and Wenkel, 2010; Seo et al., 2011a).

The above examples of competitive inhibition are reminiscent of the effects of dominant-negative alleles. Often, dominantnegative alleles are thought to "poison" the protein complexes they are part of, ultimately causing a mutant phenotype. Two separate cases of dominant-negative alleles in natural variation have recently been described in A. thaliana and in Helianthus annuus (Asteraceae). In A. thaliana, QTL mapping of natural variation in branching pattern resulted in the identification of a naturally occurring allele of the MADS box protein AGL6 that, in combination with other loci, causes reduced shoot branching. This dominant-negative allele results in single amino acid replacement (P201L) in the C-terminus, a region of the protein thought to mediate higher-order PPIs (Huang et al., 2012).

In $H$. annuus, the sunflower, three tandem duplicate homologs of the A. thaliana floral inducer FT (FLOWERING LOCUS T) underlie a single large-effect QTL for flowering time. All three paralogs show divergent expression patterns, indicative of subfunctionalization. In addition, there is a frameshift mutation in the domesticated version of one of the paralogs, HaFT1, that causes a 17 aa insertion in the encoded protein. In A. thaliana, the frameshift HaFT1 allele abrogates the early flowering phenotype (under long days) conferred by a 35S::HaFT4 transgene. This dominant-negative effect may result from disrupted PPIs between HaFT1 and its floral induction partners. The frameshifted allele is found almost exclusively in domesticated, not wild, sunflower cultivars, and there is evidence for a selective sweep at the genomic region surrounding $H a F T 1$, indicating that this altered gene may have been a target of selection during domestication (Blackman et al., 2010).

\section{ALTERED DOMAIN CONTENT}

Protein domains have been described that target proteins to particular cellular compartments [e.g., nuclear localization signals (Lange et al., 2007)]; that act as repressor or activator domains [e.g., the EAR repression domain (Ohta et al., 2001)]; that function in mediating the assembly of protein complexes [e.g., the PDZ domain (Kennedy, 1995)]; that act as post-translational modification (PTM) sites (Lusser et al., 2001); and that target proteins for destruction [e.g., the D box, (Ho et al., 2008)], to name a tiny subset of the existing diversity. The evolutionary origin of many characterized protein domains is often unclear or unexamined, except in a few cases. In a study of the evolution of plant protein domain gain and loss, Kersting et al. (2012) showed that new, plant-specific domains have emerged throughout plant history, but the highest rate of novel domain emergence was detected on the branch leading to the seed plants. This study also demonstrated that the arrangement of domains in individual proteins varies considerably, particularly at shallower phylogenetic levels. Lineage-specific domain architectures are not uncommon (Kersting et al., 2012).

Plant-specific gene lineages may possess domains present in all eukaryotes, but in land-plant-specific combinations (Xing et al., 2013). For example, the F-box and the tubulin DNA-binding domain are both found in all eukaryotes, but they are found adjacent to one another only in plants (Charoensawan et al., 2010). 
Similarly, HMG-box and AT-rich interaction domains are found in combination only in plants (Hansen et al., 2008). To catalog all characterized protein motifs and domains, and their occurrence in plant genomes, is beyond the scope of this paper. Instead, we have chosen to discuss examples where new functional domains in plant proteins have arisen through defined mechanisms, and to discuss examples where domain loss has been shown to have some defined functional consequence.

\section{NOVEL DOMAINS FROM HORIZONTAL GENE TRANSFER}

There is evidence for horizontal gene transfer (HGT) between closely allied eukaryotic species (Bergthorsson et al., 2003, 2004; Richardson and Palmer, 2007; Xi etal., 2013), for massive chloroplast-nuclear gene transfer (Martin et al., 1998, 2002; Stegemann et al., 2003), and for inter-species chloroplast movement under stress (Stegemann and Bock, 2009; Stegemann et al., 2012). Combined, these data support the notion that new genes and new domains may arise in plant genomes through HGT. Two examples in particular highlight the recruitment of domains from HGT (the MEKHLA and the AP2 domains) to key developmental processes in plants.

The AP2 domain is found in 144 Arabidopsis transcription factors with diverse, important roles in plant development and in stress response (Okamuro et al., 1997). Outside of Arabidopsis, the AP2 domain has been found in all lineages of green plants investigated - from green algae to monocots. In P. patens, four proteins with AP2 domains have been found to be important for specifying cell-type identity (Aoyama et al., 2012). The AP2 domain was initially considered to be plant-specific (Riechmann and Meyerowitz, 1998), but more sophisticated databasesearching methods revealed the existence of AP2 domains in homing endonucleases from a cyanobacterium (Trichodesmium erythraeum), a ciliate (Tetrahymena thermophila), and in two phages. No AP2 domains were detected in any other eukaryotes, apart from plants and T. thermophila. The T. erythraeum AP2 domain aligns best with plant AP2 domains, and is also capable of binding DNA in a sequence-specific manner (Magnani et al., 2004).

Multiple lines of evidence support the hypothesis that the AP2 domain arose in plant genomes through HGT from a prokaryote, rather than convergent or divergent evolution: (1) There is homology between the cyanobacterial gene and plant AP2containing genes that extends beyond the AP2 domain. (2) Very few (15\%) AP2/ERF transcription factor genes have introns. (3) The identified non-plant AP2 domains have a very similar predicted secondary structure to that of plant AP2 domains, and share more than $40 \%$ sequence identity with plant AP2 domains. (4) The nature of homing endonucleases themselves: homing endonuclease genes duplicate themselves in a process of gene conversion (Magnani et al., 2004). In addition, there is evidence that they have moved extensively, through HGT, into all of the biological kingdoms (reviewed in Stoddard, 2011).

The MEKHLA domain of REV is important for proper protein function (Prigge et al., 2005), but it is not required for transcriptional activation. Instead, the MEKHLA domain may be acting as a negative regulator of REV (Magnani and Barton, 2011). Phylogenetic analysis suggests that the MEKHLA domain, characteristic of HD-ZIP III transcription factors, found its way into plant genomes through either HGT from plant-associated bacteria, or through mass nuclear transfer from the early chloroplast (Martin et al., 2002; Mukherjee and Buerglin, 2006).

The evolution of the AP2 and MEKHLA domains demonstrates how new domains may arise and adopt important regulatory roles in plant development. Both domains were recruited into plant genomes at deep nodes in their phylogenetic histories: AP2 and MEKHLA domains are found in all plants, including the green alga Chlamydomonas. Given the hypothesized widespread occurrence of HGT in plant genomes (Richardson and Palmer, 2007), these examples may not be remarkable. Careful phylogenetic analysis, focused on particular domains rather than genes, may well reveal many more horizontally transferred protein domains.

\section{NOVEL DOMAINS FROM FRAMESHIFT MUTATIONS}

The B class MADS box genes AP3 and PI are key for controlling petal and stamen development in many flowering plants (Coen and Meyerowitz, 1991; Vandenbussche et al., 2004; Whipple et al., 2004; Drea et al., 2007; Kramer et al., 2007). There are two AP3-like genes in most core eudicots, products of a gene duplication event that generated the euAP3 and TM6 gene lineages (Kramer et al., 1999). The two gene lineages possess distinct, evolutionarily conserved C-terminal domains (Vandenbussche et al., 2003; Kramer et al., 2006). The derived euAP3 C-terminal domain (including the euAP3 motif) was probably generated through a frameshift mutation that occurred at the base of the core eudicots (Kramer et al., 2006). Where they have been investigated, the euAP3 and TM6 gene lineages have distinct but overlapping roles in floral development (Vandenbussche et al., 2004). There is some evidence that this functional distinction in the core eudicots is mediated, at least in part, by the proteins' divergent C-termini (Lamb and Irish, 2003). Frameshift mutations have arisen and been maintained in other taxa with AP3-like gene duplications, and in other gene lineages, although the functional significance of the novel motifs generated has not been extensively investigated (Litt and Irish, 2003; Vandenbussche et al., 2003; Kramer et al., 2006; Pabón-Mora et al., 2012).

\section{DOMAIN LOSS}

Domain loss can be detected by phylogenetic analysis of individual protein families (Zhang and Wang, 2005; Finet et al., 2013), and a large-scale analysis of protein domain evolution in plants revealed that domain loss occurs fairly frequently in plant lineages, particularly at family and subfamily-specific phylogenetic levels (Kersting et al., 2012). Although relatively easy to detect, the functional significance of these novel domain architectures is difficult to assess. Three examples where the function of domain loss has been shown involve the terpene synthase biosynthetic enzymes (Hillwig et al., 2011); the E class MADS box transcription factors from rice (Christensen and Malcomber, 2012); and a NAC domain transcription factor from $A$. thaliana (Li et al., 2011).

Plant terpene synthases are thought to have evolved from diterpene synthases, essential enzymes in the gibberellin synthesis pathway. Huge chemical diversity exists in plants, partly because of the evolution of the terpene synthases. Terpene synthases have lost the central $\gamma$-domain characteristic of diterpene synthases. There is some evidence that $\gamma$-domain loss has occurred multiple times in various taxonomic groups, but it remains uncertain whether 
$\gamma$-loss was a single evolutionary event, or the result of several parallel domain losses (Hillwig et al., 2011).

The E class MADS box genes of rice Leafy hull sterile ( $L H S$ ) and OsMADS5 (OSM5) are the products of a gene duplication event that occurred early on in the diversification of the grasses (Christensen and Malcomber, 2012). Lhs1 mutants are characterized by leafy lemmas, paleas, and lodicules, fewer stamens, and occasional extra pistils and/or florets (Jeon et al., 2000). osm5 mutants show a very mild floral phenotype: partial fusion between the lodicules (petal homologs) and the lemma and palea (sepal homologs; Agrawal et al., 2005). There is a premature stop codon in OSM5, shortly after the DNA-binding MADS domain of the protein. Perhaps because of this truncation, postdating the gene duplication event that produced OSM5, OSM5 has a different spectrum of binding partners to LHS, which may contribute to its divergent function (Cui et al., 2010; Christensen and Malcomber, 2012).

The Cvi and Ler accessions of Arabidopsis have differing sensitivities to fructose. A QTL for fructose sensitivity was cloned, and it corresponds to a gain-of-function mutation in a NAC domain transcription factor gene (ANAC089). A premature stop codon in the Cvi allele leads to a truncated protein, missing a predicted membrane-bound domain (Li et al., 2011). In some NAC transcription factors, the membrane-bound domain serves to retain the protein in the cytoplasm in an inactive form (Seo et al., 2008). Without the membrane-anchoring domain, ANAC089 is constitutively active in the nucleus, probably as a transcriptional activator. Although it does demonstrate some of the molecular diversity that might be tolerated in nature, the Cvi allele of ANAC089 is rare, and possibly deleterious (Li et al., 2011).

\section{ALTERED ACTIVITY OF TRANSCRIPTIONAL REPRESSORS AND ACTIVATORS}

FT (FLOWERING LOCUS T) and TFL (TERMINAL FLOWER) are distantly related paralogous regulators of flowering in Arabidopsis. FT is a floral integrator, and FT expression induces flowering. TFL is a floral repressor and maintains indeterminate growth of the shoot apical meristem. This functional distinction between FT and TFL has been separately traced to a single amino acid difference in the predicted anion-binding pocket (Y85 in FT and H88 in TFL; Hanzawa et al., 2005) and to differences in an external protein loop termed "segment B" (Ahn et al., 2006). There is evidence that FT and TFL exert their respective functions as part of transcriptional activator and repressor complexes (reviewed in Taoka et al., 2013). Y85 in FT and H88 in TFL may be working to recruit transcriptional coactivators or corepressors, either alone or in concert with "segment B" (Ahn et al., 2006; Taoka et al., 2013).

Similarly, two FT homologs in Beta vulgaris (sugarbeet) show antagonistic functions in the regulation of flowering. BvFT2 function is conserved with $F T$ and acts as a floral promoter while $B v F T 1$ represses flowering. The antagonistic functions of BvFT1 and BvFT2 have been traced to differences at three amino acid residues in "segment B." BvFT1 and BvFT2 appear to be the products of a relatively recent gene duplication event: BvFT2 homologs have not been found outside of the genus Beta (Pin et al., 2010).

Some soybean (Glycine max, Fabaceae) cultivars display a narrow leaflet phenotype, long been known to be controlled by a single gene, $\ln$. $L n$ has been mapped to a genomic region that includes a single gene - Gm-JAG1-a homolog of the A. thaliana zinc-finger gene JAGGED. A single amino acid substitution (D9H) in the transcriptional repressor EAR motif of $G m-J A G 1$ is likely to be the causal In mutation, rendering Gm-JAG1 non- or hypofunctional (Jeong et al., 2012). In addition to altering leaf morphology, the In mutation affects the number of seeds per fruit (You et al., 1995; Dinkins et al., 2002). This example highlights how pleiotropic protein mutations may be tolerated and maintained in populations, possibly because of some fitness advantage. In this case, a fitness advantage may be conferred by the higher seed set of the $L n / l n$ heterozygote (Dinkins et al., 2002).

Teosinte glume architecture1 (tga1), an SBP-domain transcription factor, has been identified as a key locus in the domestication of maize from its wild progenitor, teosinte (Wang et al., 2005). Morphological differences between maize and teosinte ears are probably caused by a single coding change (K6N) in Tgal. This single amino acid change alters the biochemical function of TGA1, but the exact mechanism of this change remains unclear (Preston et al., 2012). Given the degree of morphological change associated with this single amino acid change, it is reasonable to hypothesize that TGA1 is a transcriptional activator, activating the set of genes responsible for the development of teosinte-like glume and inflorescence morphology. The single amino acid change observed in maize was sufficient to abolish, or significantly alter, this role of TGA1 (Wang et al., 2005).

\section{ALTERED PROTEIN STABILITY}

Protein degradation is one common mechanism of posttranslational gene regulation. In plants, polyubiquitylation of proteins, followed by proteolysis mediated by the $26 \mathrm{~S}$ proteasome, is a particularly prevalent mechanism of post-translational regulation (Vierstra, 2003). Examples of altered protein stability, possibly because of altered polyubiquitylation and degradation, have been observed in the light-sensing cryptochromes and phytochromes, known to be degraded in a light- and ubiquitin-dependent manner (El-Assal et al., 2001; Maloof et al., 2001; Filiault et al., 2008).

Light responses, such as flowering time, vary considerably amongst $A$. thaliana accessions (Maloof et al., 2001). Multiple independent inactivations of FRIGIDA and FLOWERING LOCUS $C$ have been identified in the study of natural variation in flowering time (reviewed in Alonso-Blanco et al., 2009), but structural changes in light-sensing cryptochromes and phytochromes have also been implicated. For example, a novel allele of CRYPTOCHROME-2 (CRY2) underlies a large-effect QTL controlling daylength sensitivity (El-Assal et al., 2001). A single missense amino acid substitution in CRY2 (V367M) results in a more stable protein as compared to the more common Ler allele (El-Assal et al., 2001). The same amino acid substitution in CRY2 (V367M) is also associated with shorter fruits, and decreased ovule number (El-Assal et al., 2004). A single amino acid (M548T) substitution in the phytochrome protein PHYA underlies reduced far-red light sensitivity in the Lm-2 accession of $A$. thaliana (Maloof et al., 2001). The substituted amino acid is able to affect multiple aspects of PHYA function: the photochemical properties of Lm-2 PHYA are affected by the M548T substitution; Lm-2 PHYA levels remained high in the light; and Lm-2 PHYA showed 
reduced autophosphorylation activity (Maloof etal., 2001). It is conceivable that the observed amino acid substitutions in both CRY2 and PHYA are interfering with some aspect of the phosphorylation, polyubiquitination, and 26S-mediated protein degradation pathway.

Hilscher et al. (2009) surveyed naturally occurring A. thaliana accessions for variation in trichome density. A single amino acid change, K19E, in the MYB domain transcription factor gene ENHANCER OF TRY AND CPC 2 (ETC2), underlies one large effect trichome density QTL. K19, although highly conserved in single-repeat R3 MYB proteins, is not in a characterized protein domain, but may represent an ubiquitination site. In the lowdensity accessions, where this lysine is replaced with a glutamate, ubiquitination of the ETC2 repressor may have been reduced or lost, resulting in higher stability of ETC2 and, ultimately, fewer trichomes (Hilscher et al., 2009). An interesting point arising from this study is the relationship between trichomes and root hairs. ETC2 is the only characterized single-repeat R3 MYB gene family member that affects trichome density, but not root hair density. The K19E replacement, found at a relatively high frequency in naturally occurring accessions, may be tolerated because it occurs in a gene with low pleiotropy (Hilscher et al., 2009).

\section{HYPOMORPHIC AND HYPERMORPHIC ALLELES}

Mutations that either decrease or increase protein function can be termed hypomorphs or hypermorphs, respectively (Muller, 1932). Examples of both hypomorphic and hypermorphic alleles in natural variation in a number of $A$. thaliana phenotypes have been described.

Hyperaccumulation and salt tolerance have repeatedly been associated with altered functionality of transporters and biosynthetic enzymes. Amino acid substitutions in conserved domains of HMA3 and HMA5 underlie A. thaliana QTL for Cd accumulation (Chao etal., 2012) and $\mathrm{Cu}$ tolerance (Kobayashi etal., 2008), respectively. The amino acid substitutions in HMA3 result in a hypofunctional translocator and, ultimately, higher $\mathrm{Cd}$ accumulation. Similarly, high sulfate accumulation in the Shahdara accession of $A$. thaliana (Loudet et al., 2007) and differences in salt tolerance between rice accessions (Ren et al., 2005) have been separately associated with hypomorphic alleles.

The late flowering Sy- 0 accession of $A$. thaliana is distinctive in its morphology. The basal rosette is enlarged, aerial rosettes form in the axils of stem leaves, and early floral meristems revert to indeterminate growth (Poduska et al., 2003). A single amino acid replacement in the pre-mRNA processing factor, HUA2, is responsible for the majority of the Sy-0 aerial rosette phenotype. HUA2 has been shown to positively regulate the flowering genes $A G$ (floral patterning, floral determinacy) and FLC (flowering time). In the Sy- 0 accession, $A G$ function is attenuated, and FLC expression is enhanced. Thus, the single $S y-0$ amino acid replacement in HUA2 (K525E) is a partial loss-of-function (hypomorphic) allele with respect to its effects on $A G$, and a gain-of-function (hypermorphic) allele with respect to FLC expression. Although the morphological phenotype exhibited by the Sy- 0 accession is not rare, the nucleotide polymorphism that causes the K525E amino acid replacement is rare. In a survey of $113 \mathrm{~A}$. thaliana accessions, only Sy-0 was found to possess the causative single nucleotide polymorphism (SNP; Wang et al., 2007).

Naturally occurring accessions of $A$. thaliana exhibit considerable diversity in the rate of leaf production. One accession, Est-1, shows both slower leaf production, as well as extensive necrosis on older leaves. Both slower leaf production and late onset leaf necrosis in Est-1 are due to gain of function (hypermorphic) mutations in a single gene, ACCELERATED CELL DEATH6 (ACD6). $A C D 6$ encodes a transmembrane protein involved in the regulation of salicylic acid accumulation and the defense response. The increased activity of ACD6 observed in Est-1, and 14 other A. thaliana accessions, may confer enhanced pathogen resistance, but with costs. Enhanced pathogen resistance comes at the price of reduced biomass (fewer, smaller leaves), which in turn is associated with fitness costs (Abreu and Munné-Bosch, 2009; Todesco et al., 2010).

\section{MICRO- vS. MACROEVOLUTIONARY DYNAMICS IN PROTEIN EVOLUTION}

We have divided our discussion into six broad categories of protein change, but we could also have divided the examples according to the evolutionary scale at which the change was predicted to occur (Table 1). Evolutionary change can be considered microevolutionary (occurring within a single population or species) or macroevolutionary (transcending species boundaries; Gould, 2002). When protein evolution is considered with these categories in mind, do certain changes occur preferentially on a micro- or macroevolutionary scale? It must be stated that all evolutionary events probably happen at a microevolutionary scale, within a population, but the scale at which we observe these events changes. Some categories of change were detected at both micro- and macroevolutionary scales, including active site evolution of enzymes, altered activity as a transcriptional activator or a repressor, and the evolution of PPIs. The evolution of competitive inhibition appears to occur primarily on macroevolutionary time scales, while dominant negatives were detected exclusively at a microevolutionary scale. Dominant-negative alleles and competitive inhibition are similar in character, and it is conceivable that dominant-negative alleles might represent the first step on one pathway to the evolution of competitive inhibition. Domain loss, observed at both micro- and macroevolutionary scales, may represent another pathway leading to competitive inhibition.

The existing examples of DNA-binding domain evolution occur on very deep, macroevolutionary time scales. Similarly, there were no examples of novel domains at microevolutionary timescales. Are these events so rare, and so often deleterious, that they are seldom uncovered in the study of populationlevel natural variation? Or, would systematic analysis of DNAbinding or protein domain architecture at a population-level reveal microevolutionary examples?

At the opposite side of the spectrum, but similarly illuminating, lie changes that were detected predominantly on microevolutionary scales. In addition to dominant negatives, hypo- and hypermorphic alleles and altered protein stability were detected almost exclusively on microevolutionary, or intrageneric, time scales. These examples may suggest where to look for innovation on macroevolutionary scales. These changes, sometimes causing 
drastically altered phenotypes, are tolerated in natural environments. Often it is difficult to distinguish functional and phylogenetic signal from the noise in evolutionary analyses of gene families. Perhaps looking for altered stability of evolutionary variants, for example, might yield insight into the functional consequences of molecular evolution. Altered protein stability, in particular, may represent one way in which a protein's function might stay intact, but the protein may persist for a shorter or longer period of time. This could conceivably result in a heterochronic shift (Klingenberg, 1998) in a particular trait.

\section{CONCLUSIONS}

One interesting point arising from our survey of the existing literature is that proteins can change in a number of ways that were not uncovered here. One class of changes, in particular, that remained elusive was PTMs. The examples of altered protein stability may have ultimately been because of altered PTMs, but that remains to be determined. The absence of altered PTMs in the study of protein evolution is perhaps because many of the PTMs of individual extant proteins are still incompletely understood, so assessing PTMs in an evolutionary context remains extremely challenging. In the case of QTL cloning, PTM alterations may not be tolerated very often, and will therefore vary only very rarely on microevolutionary scales. Examples do arise in mutant analyses (Soppe et al., 2000; Kim et al., 2006), so more cases of natural variation in PTMs may be forthcoming. PTMs have clearly arisen and diversified in proteins and the study of their evolution represents an interesting area of future exploration.

Although many of the discussed changes primarily affect transcription factors, the phenotypic outcomes of these changes are

\section{REFERENCES}

Abreu, M. E., and Munné-Bosch, S. (2009). Salicylic acid deficiency in NahG transgenic lines and sid2 mutants increases seed yield in the annual plant Arabidopsis thaliana. J. Exp. Bot. 60, 1261-1271. doi: 10.1093/jxb/ern363

Agrawal, G. K., Abe, K., Yamazaki, M. Miyao, A., and Hirochika, H. (2005). Conservation of the E-function for floral organ identity in rice revealed by the analysis of tissue cultureinduced loss-of-function mutants of the OsMADS1 gene. Plant Mol. Biol. 59, 125-135. doi: 10.1007/s11103005-2161-y

Aharoni, A., Gaidukov, L., Khersonsky, O., Gould, S. M., Roodveldt, C., and Tawfik, D. S. (2004). The 'evolvability' of promiscuous protein functions. Nat. Genet. 37, 73-76.

Ahn, J. H., Miller, D., Winter, V. J., Banfield, M. J., Lee, J. H., Yoo, S. Y., et al. (2006). A divergent external loop confers antagonistic activity on floral regulators FT and TFL1. EMBO J. 25, 605-614. doi: 10.1038/sj.emboj.7600950

Airoldi, C. A., Bergonzi, S., and Davies, B. (2010). Single amino acid change alters the ability to specify male or female organ identity. Proc. Natl. Acad. Sci. U.S.A. 107, 18898-18902. doi: 10.1073/pnas.1009050107

Alonso-Blanco, C., Aarts, M. G., Bentsink, L., Keurentjes, J. J., Reymond, M., Vreugdenhil, D., et al. (2009). What has natural variation taught us about plant development, physiology, and adaptation? Plant Cell 21, 1877-1896. doi: 10.1105/ tpc.109.068114

Anke, S., Niemüller, D., Moll, S., Hänsch, R., and Ober, D. (2004). Polyphyletic origin of pyrrolizidine alkaloids within the Asteraceae. Evidence from differential tissue expression of homospermidine synthase. Plant Physiol. 136, 4037-4047. doi: 10.1104/pp.104.052357

Anthony, R. G., Waldin, T. R., Ray, J. A., Bright, S. W. J., and Hussey, P. J. (1998). Herbicide resistance caused by spontaneous mutation of the cytoskeletal protein tubulin. Nature 393, 260-263. doi: 10.1038/ 30484

Aoyama, T., Hiwatashi, Y., Shigyo, M., Kofuji, R., Kubo, M., Ito, M., et al. (2012). AP2-type transcription factors determine stem cell identity

often vastly different. Even within one class of change, altered PPIs, one altered interaction affects trichome density in Arabidopsis, another affects floral morphology in Thalictrum. Although similar biochemical changes might have occurred, the ultimate phenotypes on which natural selection might act are distinct and not evolutionarily equivalent.

Genetic analysis (QTL cloning) has deepened our understanding of the molecular underpinnings of phenotypic diversity to a considerable degree. As more QTL are uncovered and cloned, no doubt this understanding will grow ever deeper. But systematically cloning QTLs will not tell us everything there is to know about the evolution of plant form and function. It remains important to combine all of the strategies available to us, including phylogenetic analyses of gene families, structural analyses, and functional analyses of proteins in an evolutionary context, in order to gain a more complete picture of protein evolution. It would also be extremely informative to know how many of the QTL that have been cloned confer adaptive phenotypes, or have the potential to be adaptive under certain conditions. Although challenging, field and laboratory selection tests on some of the more promising accessions would no doubt yield fascinating results.

\section{ACKNOWLEDGMENTS}

We would like to thank the three reviewers for helpful suggestions on an earlier version of the manuscript. We gratefully acknowledge support from the National Science Foundation (IOS-1025121 to Clinton J. Whipple). Finally, we would like to apologize to those authors whose work we have inadvertently omitted or could not review at length due to space limitations.

in the moss Physcomitrella patens. Development 139, 3120-3129. doi: 10.1242/dev.076091

Arnaud, N., Lawrenson, T., Òstergaard, L., and Sablowski, R. (2011) The Same regulatory point mutation changed seed-dispersal structures in evolution and domestication. Curr. Biol. 21, 1215-1219. doi: 10.1016/j.cub.2011.06.008

Balkunde, R., Pesch, M., and Hulskamp, M. (2010). Trichome patterning in Arabidopsis thaliana from genetic to molecular models. Curr. Top. Dev. Biol. 91, 299-321. doi: 10.1016/S0070-2153(10)91010-7

Barrett, R. D., and Hoekstra, H. E. (2011). Molecular spandrels: tests of adaptation at the genetic level. Nat. Rev. Genet. 12, 767-780. doi: $10.1038 / \mathrm{nrg} 3015$

Benderoth, M., Textor, S., Windsor, A. J., Mitchell-Olds, T., Gershenzon, J., and Kroymann, J. (2006). Positive selection driving diversification in plant secondary metabolism. Proc. Natl. Acad. Sci. U.S.A. 103, 9118-9123. doi: 10.1073/pnas.0601738103

Bergthorsson, U., Adams, K. L., Thomason, B., and Palmer, J. D. (2003). Widespread horizontal transfer of mitochondrial genes in flowering plants. Nature 424, 197-201. doi: 10.1038 /nature 01743

Bergthorsson, U., Richardson, A. O., Young, G. J., Goertzen, L. R., and Palmer, J. D. (2004). Massive horizontal transfer of mitochondrial genes from diverse land plant donors to the basal angiosperm Amborella. Proc. Natl. Acad. Sci. U.S.A. 101, 17747-17752. doi: 10.1073/pnas.0408336102

Blackman, B. K., Strasburg, J. L., Raduski, A. R., Michaels, S. D., and Rieseberg, L. H. (2010). The role of recently derived FT paralogs in sunflower domestication. Curr. Biol. 20, 629-635. doi: 10.1016/j.cub.2010.01.059

Bornberg-Bauer, E., Huylmans, A.K., and Sikosek, T. (2010). How do new proteins arise? Curr. Opin. Struct. Biol. 20, 390-396. doi: 10.1016/j.sbi.2010.02.005

Carroll, S. (2000). Endless forms: the evolution of gene regulation and morphological diversity. Cell 101 , 577. doi: 10.1016/S00928674(00)80868-5

Carroll, S. B. (2005). Evolution at two levels: on genes and form. 
PLoS Biol. 3:e245. doi: 10.1371/journal.pbio.0030245

Carroll, S. B. (2008). Evo-devo and an expanding evolutionary synthesis: a genetic theory of morphological evolution. Cell 134, 25-36. doi: 10.1016/j.cell.2008.06.030

Causier, B., Castillo, R., Zhou, J., Ingram, R., Xue, Y., SchwarzSommer, Z., et al. (2005). Evolution in action: following function in duplicated floral homeotic Genes. Curr. Biol. 15, 1508-1512. doi: 10.1016/j.cub.2005.07.063

Chao, D. Y., Silva, A., Baxter, I., Huang, Y. S., Nordborg, M., Danku, J., et al. (2012). Genome-wide association studies identify heavy metal ATPase 3 as the primary determinant of natural variation in leaf cadmium in Arabidopsis thaliana. PLoS Genetics 8:e1002923. doi: 10.1371/ journal.pgen.1002923

Charoensawan, V., Wilson, D., and Teichmann, S. A. (2010). Lineagespecific expansion of DNA-binding transcription factor families. Trends Genet. 26, 388-393. doi: 10.1016/j. tig.2010.06.004

Christensen, A., and Malcomber, S. (2012). Duplication and diversification of the LEAFY HULL STERILE1 and Oryza sativa MADS5 SEPALLATA lineages in graminoid Poales. Evodevo 3, 4. doi: 10.1186/20419139-3-4

Coen, E. S., and Meyerowitz, E. M. (1991). The war of the whorls: genetic interactions controlling flower development. Nature 353, 31-37. doi: 10.1038/353031a0

Corley, S. B., Carpenter, R., Copsey, L., and Coen, E. (2005). Floral asymmetry involves an interplay between TCP and MYB transcription factors in Antirrhinum. Proc. Natl. Acad. Sci. U.S.A. 102, 5068-5073. doi: 10.1073/ pnas. 0501340102

Cui, H., Levesque, M. P., Vernoux, T., Jung, J. W., Paquette, A. J., Gallagher, K. L., etal. (2007). An evolutionarily conserved mechanism delimiting SHR movement defines a single layer of endodermis in plants. Science 316, 421-425. doi: 10.1126/science.1139531

Cui, R., Han, J., Zhao, S., Su, K., Wu, F., Du, X., et al. (2010). Functional conservation and diversification of class $\mathrm{E}$ floral homeotic genes in rice (Oryza sativa). Plant J. 61, 767781. doi: 10.1111/j.1365-313X.2009. 04101.x

Davies, B., Motte, P., Keck, E., Saedler, H., Sommer, H., and Schwarz-Sommer, Z. (1999). PLENA and FARINELLI: redundancy and regulatory interactions between two
Antirrhinum MADS-box factors controlling flower development. $E M B O$ J. 18, 4023-4034. doi: 10.1093/ emboj/18.14.4023

Dinkins, R. D., Keim, K. R., Farno, L. and Edwards, L. H. (2002). Expression of the narrow leaflet gene for yield and agronomic traits in soybean. J. Hered. 93, 346-351. doi: 10.1093/jhered/93.5.346

Dixon, R. A. (2001). Natural products and plant disease resistance. Nature 411, 843-847. doi: 10.1038/35081178

Drea, S., Hileman, L. C., De Martino, G., and Irish, V. F. (2007). Functional analyses of genetic pathways controlling petal specification in poppy. Development 134, 4157-4166. doi: 10.1242/dev.013136

El-Assal, S. E., Alonso-Blanco, C., Hanhart, C. J., and Koornneef, M. (2004). Pleiotropic effects of the Arabidopsis cryptochrome2 allelic variation underlie fruit trait-related QTL. Plant Biol. 6, 370-374. doi: 10.1055/s2004-820890

El-Assal, S. E., Alonso-Blanco, C., Peeters, A. J., Raz, V., and Koornneef, M. (2001). A QTL for flowering time in Arabidopsis reveals a novel allele of CRY2. Nat. Genet. 29, 435-440. doi: 10.1038/ng767

Filiault, D. L., Wessinger, C. A., Dinneny, J. R., Lutes, J., Borevitz, J. O., Weigel, D., et al. (2008). Amino acid polymorphisms in Arabidopsis phytochrome B cause differential responses to light. Proc. Natl. Acad. Sci. U.S.A. 105, 3157-3162. doi: 10.1073/pnas.0712174105

Finet, C., Berne-Dedieu, A., Scutt, C. P., and Marletaz, F. (2013). Evolution of the ARF gene family in land plants: old domains, new tricks. Mol. Biol. Evol. 30, 45-56. doi: 10.1093/mol$\mathrm{bev} / \mathrm{mss} 220$

Flagel, L. E., and Wendel, J. F. (2009). Gene duplication and evolutionary novelty in plants. New Phytol. 183, 557-564. doi: 10.1111/j.14698137.2009.02923.x

Floyd, S. K., Zalewski, C. S., and Bowman, J. L. (2006). Evolution of class III homeodomain-leucine zipper genes in streptophytes. Genetics 173, 373-388. doi: 10.1534/genetics.105.054239

Fourquin, C., Del Cerro, C., Victoria, F. C., Vialette-Guiraud, A., De Oliveira, A. C., and Ferrándiz, C. (2013). A change in SHATTERPROOF protein lies at the origin of a fruit morphological novelty and a new strategy for seed dispersal in Medicago genus. Plant Physiol. 162, 907-917. doi: 10.1104/pp.113.217570

Fridman, E., Carrari, F., Liu, Y. S., Fernie, A. R., and Zamir, D.
(2004). Zooming in on a quantitative trait for tomato yield using interspecific introgressions. Science 305 1786-1789. doi: 10.1126/science. 1101666

Galimba, K. D., Tolkin, T. R., Sullivan, A. M., Melzer, R., Theissen, G., and Di Stilio, V. S. (2012). Loss of deeply conserved C-class floral homeotic gene function and $\mathrm{C}$ - and E-class protein interaction in a double-flowered ranunculid mutant. Proc. Natl. Acad. Sci. U.S.A. 109, E2267-E2275. doi 10.1073/pnas.1203686109

Gherardini, P. F., Wass, M. N., HelmerCitterich, M., and Sternberg, M. J. E. (2007). Convergent evolution of enzyme active sites is not a rare phenomenon. J. Mol. Biol. 372, 817-845 doi: 10.1016/j.jmb.2007.06.017

Gould, S. J. (2002). The Structure of Evolutionary Theory. Harvard University Press.

Gould, S. J., and Vrba, E. S. (1982). Exaptation - a missing term in the science of form. Paleobiology 8, 4-15.

Gramzow, L., Ritz, M. S., and Theissen, G. (2010). On the origin of MADS-domain transcription factors. Trends Genet. 26, 149-153. doi: 10.1016/j.tig.2010.01.004

Greenhagen, B. T., O'maille, P. E., Noel, J. P., and Chappell, J. (2006). Identifying and manipulating structural determinates linking catalytic specificities in terpene synthases. Proc Natl. Acad. Sci. U.S.A. 103, 9826 9831. doi: $10.1073 /$ pnas. 0601605103

Hansen, F. T., Madsen, C. K., Nordland, A. M., Grasser, M., Merkle, T., and Grasser, K. D. (2008). A novel family of plant DNA-binding proteins containing both HMG-box and AT-rich interaction domains. Biochemistry 47, 13207-13214. doi: 10.1021/bi801772k

Hanzawa, Y., Money, T., and Bradley, D. (2005). A single amino acid converts a repressor to an activator of flowering. Proc. Natl. Acad. Sci. U.S.A. 102, 7748-7753. doi: 10.1073/ pnas.0500932102

Hillwig, M. L., Xu, M., Toyomasu, T., Tiernan, M. S., Wei, G., Cui, G. et al. (2011). Domain loss has independently occurred multiple times in plant terpene synthase evolution. Plant J. 68, 1051-1060. doi: 10.1111/j.1365-313X.2011.04756.x

Hilscher, J., Schlûtterer, C., and Hauser, M.-T. (2009). A single amino acid replacement in ETC2 shapes trichome patterning in natural Arabidopsis populations. Curr. Biol. 19, 1747-1751. doi: 10.1016/j. cub.2009.08.057

Himi, S., Sano, R., Nishiyama, T., Tanahashi, T., Kato, M., Ueda, K., et al. (2001). Evolution of MADS-box gene induction by FLO/LFY genes. J. Mol. Evol. 53, 387-393. doi: 10.1007/s002390010228

Ho, M., Ou, C., Chan, Y.-R., Chien, C.-T., and Pi, H. (2008). The utility F-box for protein destruction. Cell. Mol. Life Sci. 65, 1977-2000. doi: 10.1007/s00018-008-7592-6

Hoekstra, H. E., and Coyne, J. A. (2007). The locus of evolution: evo devo and the genetics of adaptation. Evolution 61, 995-1016. doi: 10.1111/j.15585646.2007.00105.x

Hong, S. Y., Kim, O. K., Kim, S. G., Yang, M. S., and Park, C. M. (2011). Nuclear import and DNA binding of the ZHD5 transcription factor is modulated by a competitive peptide inhibitor in Arabidopsis. J. Biol. Chem. 286, 1659-1668. doi: 10.1074/jbc.M110.167692

Honma, T., and Goto, K. (2000). The Arabidopsis floral homeotic gene PISTILLATA is regulated by discrete ciselements responsive to induction and maintenance signals. Development 127, 2021-2030.

Honma, T., and Goto, K. (2001). Complexes of MADS-box proteins are sufficient to convert leaves into floral organs. Nature 409, 525-529. doi: $10.1038 / 35054083$

Huang, X., Effgen, S., Meyer, R. C., Theres, K., and Koornneef, M. (2012). Epistatic natural allelic variation reveals a function of AGAMOUS-LIKE6 in axillary bud formation in Arabidopsis. Plant Cell 24, 2364-2379. doi: 10.1105/tpc. 112.099168

Immink, R. G., Kaufmann, K., and Angenent, G. C. (2010). The 'ABC' of MADS domain protein behaviour and interactions. Semin. Cell Dev. Biol. 21, 87-93. doi: 10.1016/j.semcdb.2009.10.004

Jeon, J., Jang, S., Lee, S., Nam, J., Kim, C., Lee, S., et al. (2000). leafy hull sterile1 is a homeotic mutation in a rice MADS box gene affecting rice flower development. Plant Cell 12, 871-884. doi: $10.1105 /$ tpc. 12.6 .871

Jeong, N., Suh, S. J., Kim, M.-H., Lee, S., Moon, J.-K., Kim, H. S., et al. (2012). Ln is a key regulator of leaflet shape and number of seeds per pod in soybean. Plant Cell 24, 4807-4818. doi: 10.1105/tpc.112.104968

Jin, J., Huang, W., Gao, J. P., Yang, J., Shi, M., Zhu, M. Z., etal. (2008). Genetic control of rice plant architecture under domestication. Nat. Genet. 40, 1365-1369. doi: 10.1038/ ng.247

Kaltenegger, E., Eich, E., and Ober, D. (2013). Evolution of homospermidine synthase in the convolvulaceae: 
a story of gene duplication, gene loss, and periods of various selection pressures. Plant Cell 25, 1213-1227. doi: 10.1105/tpc.113.109744

Kennedy, M. B. (1995). Origin of PDZ (DHR, GLGF) domains. Trends Biochem. Sci. 20, 350. doi: 10.1016/S0968-0004(00)89074-X

Kersting, A. R., Bornberg-Bauer, E. Moore, A. D., and Grath, S. (2012). Dynamics and adaptive benefits of protein domain emergence and arrangements during plant genome evolution. Genome Biol. Evol. 4, 316329. doi: 10.1093/gbe/evs004

Kim, H. J., Ryu, H., Hong, S. H., Woo, H. R., Lim, P. O., Lee, I. C., et al. (2006). Cytokinin-mediated control of leaf longevity by AHK3 through phosphorylation of ARR2 in Arabidopsis. Proc. Natl. Acad. Sci. U.S.A. 103, 814-819. doi: 10.1073/pnas.05051 50103

Kim, J., Harter, K., and Theologis, A. (1997). Protein-protein interactions among the Aux/IAA proteins. Proc. Natl. Acad. Sci. U.S.A. 94, 11786-11791. doi: 10.1073/pnas.94. 22.11786

Kim, Y.-S., Kim, S.-G., Lee, M., Lee, I., Park, H.-Y., Seo, P. J., et al. (2008). HD-ZIP III activity is modulated by competitive inhibitors via a feedback loop in Arabidopsis shoot apical meristem development. Plant Cell 20, 920-933. doi: 10.1105/tpc.107.057448

Klingenberg, C. P. (1998). Heterochrony and allometry: the analysis of evolutionary change in ontogeny. Biol. Rev. 73, 79-123. doi: 10.1017/S000632319800512X

Kobayashi, Y., Kuroda, K., Kimura, K., Southron-Francis, J. L., Furuzawa, A., Kimura, K., et al. (2008). Amino acid polymorphisms in strictly conserved domains of a P-type ATPase HMA5 are involved in the mechanism of copper tolerance variation in Arabidopsis. Plant Physiol. 148, 969-980. doi: 10.1104/pp.108.119933

Kramer, E. M., Dorit, R. L., and Irish, V. F. (1999). Molecular evolution of genes controlling petal and stamen development: duplication and divergence within the APETALA3 and PISTILLATA MADS-box gene lineages. Genetics 151, 915-915.

Kramer, E. M., Holappa, L., Gould, B., Jaramillo, M. A., Setnikov, D., and Santiago, P. M. (2007). Elaboration of $B$ gene function to include the identity of novel floral organs in the lower eudicot Aquilegia. Plant Cell 19, 750-766. doi: 10.1105/tpc.107. 050385

Kramer, E. M., Su, H.-J., Wu, C.-C., and Hu, J.-M. (2006). A simplified explanation for the frameshift mutation that created a novel C-terminal motif in the APETALA3 gene lineage. BMC Evol. Biol. 6:30. doi: 10.1186/1471-2148-6-30

Kuittinen, H., Niittyvuopio, A., Rinne, P., and Savolainen, O. (2008). Natural variation in Arabidopsis lyrato vernalization requirement conferred by a FRIGIDA indel polymorphism. Mol. Biol. Evol. 25, 319-329. doi: 10.1093/molbev/msm257

Lamb, R. S., and Irish, V. F (2003). Functional divergence within the APETALA3/PISTILLATA floral homeotic gene lineages. Proc. Natl. Acad. Sci. U.S.A. 100, 6558-6563. doi: 10.1073/pnas.0631708100

Lange, A., Mills, R. E., Lange, C. J., Stewart, M., Devine, S. E., and Corbett, A. H. (2007). Classical nuclear localization signals: definition, function, and interaction with importin a. J. Biol. Chem. 282, 5101-5105. doi: 10.1074/jbc.R600026200

Lange, M., Orashakova, S., Lange, S., Melzer, R., Theissen, G., Smyth, D. R., et al. (2013). The seirena B class floral homeotic mutant of California Poppy (Eschscholzia californica) reveals a function of the enigmatic PI motif in the formation of specific multimeric MADS domain protein complexes. Plant Cell 25, 438-453. doi: 10.1105/tpc.112.105809

Lenser, T., Theissen, G., and Dittrich, P. (2009). Developmental robustness by obligate interaction of class B floral homeotic genes and proteins. PLoS Comput. Biol. 5:e1000264. doi: 10.1371/journal.pcbi.1000264

Li, C., Zhou, A., and Sang, T. (2006). Rice domestication by reducing shattering. Science 311, 1936-1939. doi: 10.1126/science. 1123604

Li, G.-S., Meng, Z., Kong, H.-Z., Chen, Z.-D., Theissen, G., and Lu, A.-M. (2005). Characterization of candidate class A, B and E floral homeotic genes from the perianthless basal angiosperm Chloranthus spicatus (Chloranthaceae). Dev. Genes Evol. 215, 437-449. doi: 10.1007/s00427-005-0002-2

Li, P., Wind, J. J., Shi, X., Zhang, H., Hanson, J., Smeekens, S. C., et al. (2011). Fructose sensitivity is suppressed in Arabidopsis by the transcription factor ANAC089 lacking the membrane-bound domain. Proc. Natl. Acad. Sci. U.S.A. 108, 34363441. doi: 10.1073/pnas.1018665108

Litt, A., and Irish, V. F. (2003). Duplication and diversification in the APETALA1/FRUITFULL floral homeotic gene lineage: implications for the evolution of floral development. Genetics 165, 821-833.
Loudet, O., Saliba-Colombani, V., Camilleri, C., Calenge, F., Gaudon, V. Koprivova, A., et al. (2007). Natural variation for sulfate content in Arabidopsis thaliana is highly controlled by APR2. Nat. Genet. 39, 896-900. doi: $10.1038 / \mathrm{ng} 2050$

Lusser, A., Kölle, D., and Loidl, P. (2001). Histone acetylation: lessons from the plant kingdom. Trends Plant Sci. 6, 59. doi: 10.1016/S13601385(00)01839-2

Lynch, M., O’hely, M., Walsh, B., and Force, A. (2001). The probability of preservation of a newly arisen gene duplicate. Genetics 159, 1789 1804.

Lynch, V. J., and Wagner, G. P. (2008). Resurrecting the role of transcription factor change in developmental evolution. Evolution 62, 21312154. doi: 10.1111/j.1558-5646.2008. 00440.x

Magnani, E., and Barton, M. K. (2011). A per-ARNT-sim-like sensor domain uniquely regulates the activity of the homeodomain leucine zipper transcription factor REVOLUTA in Arabidopsis. Plant Cell 23, 567-582. doi: 10.1105/tpc.110.080754

Magnani, E., and Hake, S. (2008). KNOX lost the OX: the Arabidopsis KNATM gene defines a novel class of KNOX transcriptional regulators missing the homeodomain. Plant Cell 20, 875-887. doi: 10.1105/ tpc.108.058495

Magnani, E., Sjölander, K., and Hake, S. (2004). From endonucleases to transcription factors: evolution of the AP2 DNA binding domain in plants. Plant Cell 16, 2265-2277. doi: 10.1105/tpc.104.023135

Maizel, A., Busch, M. A., Tanahashi, T., Perkovic, J., Kato, M., Hasebe, M., et al. (2005). The floral regulator LEAFY evolves by substitutions in the DNA binding domain. Science 308, 260-263. doi: 10.1126/science. 1108229

Maloof, J. N., Borevitz, J. O., Dabi, T., Lutes, J., Nehring, R. B., Redfern, J. L., etal. (2001). Natural variation in light sensitivity of Arabidopsis. Nat. Genet. 29, 441-446. doi: $10.1038 / n g 777$

Martin, W., Rujan, T., Richly, E., Hansen, A., Cornelsen, S., Lins, T., et al. (2002). Evolutionary analysis of Arabidopsis, cyanobacterial, and chloroplast genomes reveals plastid phylogeny and thousands of cyanobacterial genes in the nucleus. Proc. Natl. Acad. Sci. U.S.A. 99, 12246-12251. doi: 10.1073/pnas. 182432999

Martin, W., Stoebe, B., Goremykin, V., Hansmann, S., Hasegawa, M., and
Kowallik, K. V. (1998). Gene transfer to the nucleus and the evolution of chloroplasts. Nature 393, 162-165. doi: $10.1038 / 30234$

Mauricio, R. (1998). Costs of resistance to natural enemies in field populations of the annual plant Arabidopsis thaliana. Am. Nat. 151, 20-28. doi: 10.1086/286099

Moyroud, E., Kusters, E., Monniaux, M., Koes, R., and Parcy, F. (2010). LEAFY blossoms. Trends Plant Sci. 15, 346-352. doi: 10.1016/j.tplants.2010.03.007

Mukherjee, K., and Buerglin, T. R. (2006). MEKHLA, a novel domain with similarity to PAS domains, is fused to plant homeodomain-leucine zipper III proteins. Plant Physiol. 140, 1142-1150. doi: 10.1104/ pp. 105.073833

Muller, H. J. (1932). "Further studies on the nature and causes of gene mutations," in Proceedings of the 6th International Congress of Genetics, Ithaca, New York, 213-255.

O'Brien, P. J., and Herschlag, D. (1999). Catalytic promiscuity and the evolution of new enzymatic activities. Chem. Biol. 6, R91-R105. doi: 10.1016/S1074-5521(99)80033-7

Ohno, S. (1970). Evolution by Gene Duplication. Berlin: Springer-Verlag.

Ohta, M., Matsui, K., Hiratsu, K., Shinshi, H., and Ohme-Takagi, M. (2001). Repression domains of class II ERF transcriptional repressors share an essential motif for active repression. Plant Cell 13, 1959-1968.

Okamuro, J. K., Caster, B., Villarroel, R., Van Montagu, M., and Jofuku, K. D. (1997). The AP2 domain of APETALA2 defines a large new family of DNA binding proteins in Arabidopsis. Proc. Natl. Acad. Sci. U.S.A. 94, 7076-7081. doi: 10.1073/pnas.94.13.7076

O'Maille, P. E., Malone, A., Dellas, N., Andes Hess, B. Jr., Smentek, L., Sheehan, I., et al. (2008). Quantitative exploration of the catalytic landscape separating divergent plant sesquiterpene synthases. Nat. Chem. Biol. 4, 617-623. doi: 10.1038/ nchembio. 113

Pabón-Mora, N., Ambrose, B. A., and Litt, A. (2012). Poppy APETALA1/FRUITFULL orthologs control flowering time, branching, perianth identity, and fruit development. Plant Physiol. 158, 1685-1704. doi: 10.1104/pp.111.192104

Pelaz, S., Ditta, G., Baumann, E., Wisman, E., and Yanofsky, M. (2000). $\mathrm{B}$ and $\mathrm{C}$ floral organ identity functions require SEPALLATA MADSbox genes. Nature 405, 200-203. doi: $10.1038 / 35012103$ 
Pin, P. A., Benlloch, R., Bonnet, D., Wremerth-Weich, E., Kraft, T., Gielen, J. J., et al. (2010). An antagonistic pair of FT homologs mediates the control of flowering time in sugar beet. Science 330, 1397-1400. doi: 10.1126/science.1197004

Poduska, B., Humphrey, T., Redweik, A., and Grbić, V. (2003). The synergistic activation of FLOWERING LOCUS $\mathrm{C}$ by FRIGIDA and a new flowering gene AERIAL ROSETTE 1 underlies a novel morphology in Arabidopsis. Genetics 163, 1457-1465.

Powles, S. B., and Yu, Q. (2010). Evolution in action: plants resistant to herbicides. Annu. Rev. Plant Biol. 61, 317-347. doi: 10.1146/annurevarplant-042809-112119

Prasad, K. V. S. K., Song, B.-H., Olson-Manning, C., Anderson, J. T., Lee, C.-R., Schranz, M. E., et al. (2012). A gain-of-function polymorphism controlling complex traits and fitness in nature. Science 337, $1081-$ 1084. doi: $10.1126 /$ science. 1221636

Preston, J. C., Wang, H., Kursel, L., Doebley, J., and Kellogg, E. A. (2012). The role of teosinte glume architecture (tgal) in coordinated regulation and evolution of grass glumes and inflorescence axes. New Phytol. 193, 204-215. doi: 10.1111/j.14698137.2011.03908.x

Prigge, M. J., Otsuga, D., Alonso, J. M., Ecker, J. R., Drews, G. N., and Clark, S. E. (2005). Class III homeodomainleucine zipper gene family members have overlapping, antagonistic, and distinct roles in Arabidopsis development. Plant Cell 17, 61-76. doi: 10.1105/tpc.104.026161

Raimundo, J., Sobral, R., Bailey, P., Azevedo, H., Galego, L., Almeida, J., et al. (2013). A subcellular tug of war involving three MYB-like proteins underlies a molecular antagonism in Antirrhinum flower asymmetry. Plant J. 75, 527-538. doi: 10.1111/tpj. 12225

Reimann, A., Nurhayati, N., Backenköhler, A., and Ober, D. (2004). Repeated evolution of the pyrrolizidine alkaloidmediated defense system in separate angiosperm lineages. Plant Cell 16, 2772-2784. doi: 10.1105/tpc.104.023176

Ren, Z.-H., Gao, J.-P., Li, L.-G., Cai, X.-L., Huang, W., Chao, D.-Y., et al. (2005). A rice quantitative trait locus for salt tolerance encodes a sodium transporter. Nat. Genet. 37, 11411146. doi: $10.1038 / \mathrm{ng} 1643$

Richardson, A. O., and Palmer, J. D. (2007). Horizontal gene transfer in plants. J. Exp. Bot. 58, 1-9. doi: $10.1093 / \mathrm{jxb} / \mathrm{erl} 148$
Riechmann, J. L., Krizek, B. A., and Meyerowitz, E. M. (1996a). Dimerization specificity of Arabidopsis MADS domain homeotic proteins APETALA1, APETALA3, PISTILLATA, and AGAMOUS. Proc. Natl. Acad. Sci. U.S.A. 93, 4793-4798. doi: 10.1073/pnas.93.10.4793

Riechmann, J. L., Wang, M., and Meyerowitz, E. M. (1996b). DNAbinding properties of Arabidopsis MADS domain homeotic proteins APETALA1, APETALA3, PISTILLATA and AGAMOUS. Nucleic Acids Res. 24, 3134-3141. doi 10.1093/nar/24.16.3134

Riechmann, J. L., and Meyerowitz, E. M. (1998). The AP2/EREBP family of plant transcription factors. Biol. Chem. 379, 633-646.

Rockman, M. V. (2012). The QTN program and the alleles that matter for evolution: all that's gold does not glitter. Evolution 66, 117. doi: $10.1111 /$ j.1558-5646.2011. 01486.x

Seo, P. J., Hong, S.-Y., Kim, S.-G., and Park, C.-M. (2011a). Competitive inhibition of transcription factors by small interfering peptides. Trends Plant Sci. 16, 541-549. doi: 10.1016/j.tplants.2011.06.001

Seo, P. J., Kim, M. J., Ryu, J. Y., Jeong, E. Y., and Park, C. M. (2011b). Two splice variants of the IDD14 transcription factor competitively form nonfunctional heterodimers which may regulate starch metabolism. Nat. Commun. 2, 303. doi: 10.1038/ncomms1303

Seo, P. J., Kim, S.-G., and Park, C.-M. (2008). Membrane-bound transcription factors in plants. Trends Plant Sci. 13, 550-556. doi: 10.1016/j. tplants.2008.06.008

Simons, K. J., Fellers, J. P., Trick, H. N., Zhang, Z., Tai, Y.-S., Gill, B. S., etal. (2006). Molecular characterization of the major wheat domestication gene Q. Genetics 172, 547-555. doi: 10.1534/genetics.105. 044727

Smith, S. D., and Rausher, M. D. (2011). Gene loss and parallel evolution contribute to species difference in flower color. Mol. Biol. Evol. 28, 2799-2810. doi: 10.1093/molbev/msr109

Smith, S. D., Wang, S., and Rausher, M. D. (2013). Functional evolution of an anthocyanin pathway enzyme during a flower color transition. Mol. Biol. Evol. 30, 602-612. doi: 10.1093/molbev/mss 255

Soppe, W. J., Jacobsen, S. E., AlonsoBlanco, C., Jackson, J. P., Kakutani, T., Koornneef, M., etal. (2000). The late flowering phenotype of fwa mutants is caused by gain- of-function epigenetic alleles of a homeodomain gene. Mol. Cell. 6, 791-802. doi: 10.1016/S1097-2765 (05)00090-0

Staudt, A.-C., and Wenkel, S. (2010). Regulation of protein function by 'microProteins'. EMBO Rep. 12, 3542. doi: 10.1038/embor.2010.196

Stegemann, S., and Bock, R. (2009). Exchange of genetic material between cells in plant tissue grafts. Science 324, 649-651. doi: $10.1126 /$ science. 1170397

Stegemann, S., Hartmann, S., Ruf, S., and Bock, R. (2003). High-frequency gene transfer from the chloroplast genome to the nucleus. Proc. Natl. Acad. Sci. U.S.A. 100, 8828-8833. doi: 10.1073/pnas. 1430924100

Stegemann, S., Keuthe, M., Greiner, S., and Bock, R. (2012). Horizontal transfer of chloroplast genomes between plant species. Proc. Natl. Acad. Sci. U.S.A. 109, 2434-2438. doi 10.1073/pnas.1114076109

Stern, D. L. (2000). Perspective: evolutionary developmental biology and the problem of variation. Evolution 54, 1079-1091.

Stoddard, B. L. (2011). Homing endonucleases: from microbial genetic invaders to reagents for targeted DNA modification. Structure 19, 7-15. doi: 10.1016/j.str.2010. 12.003

Sun, T.-P. (2011). The molecular mechanism and evolution of the GAGID1-DELLA signaling module in plants. Curr. Biol. 21, R338-R345. doi: 10.1016/j.cub.2011.02.036

Symonds, V. V., Hatlestad, G., and Lloyd, A. M. (2011). Natural allelic variation defines a role for ATMYC1: trichome cell fate determination. PLoS Genet. 7:e1002069. doi: 10.1371/journal.pgen.1002069

Tanahashi, T., Sumikawa, N., Kato, M., and Hasebe, M. (2005). Diversification of gene function: homologs of the floral regulator FLO/LFY control the first zygotic cell division in the moss Physcomitrella patens. Development 132, 1727-1736. doi: 10.1242/dev.01709

Taoka, K.-I., Ohki, I., Tsuji, H., Kojima, C., and Shimamoto, K. (2013). Structure and function of florigen and the receptor complex. Trends Plant Sci. 18, 287294. doi: 10.1016/j.tplants.2013. 02.002

Todesco, M., Balasubramanian, S., Hu, T. T., Traw, M. B., Horton, M., Epple, P., etal. (2010). Natural allelic variation underlying a major fitness trade-off in Arabidopsis thaliana. Nature 465, 632-636. doi: 10.1038 /nature09083
Turner, A., Beales, J., Faure, S., Dunford, R. P., and Laurie, D. A. (2005). The pseudo-response regulator Ppd-H1 provides adaptation to photoperiod in barley. Science 310, 1031-1034. doi: 10.1126/science.1117619

Ulmasov, T., Murfett, J., Hagen, G., and Guilfoyle, T. J. (1997). Aux/IAA proteins repress expression of reporter genes containing natural and highly active synthetic auxin response elements. Plant Cell 9, 1963-1971. doi: 10.1105/tpc.9.11.1963

Vandenbussche, M., Theissen, G., Van De Peer, Y., and Gerats, T. (2003). Structural diversification and neo-functionalization during floral MADS-box gene evolution by C-terminal frameshift mutations. Nucleic Acids Res. 31, 4401-4409. doi: 10.1093/nar/gkg642

Vandenbussche, M., Zethof, J., Royaert, S., Weterings, K., and Gerats, T. (2004). The duplicated B-class heterodimer model: whorl-specific effects and complex genetic interactions in Petunia hybrida flower development. Plant Cell 16, 741-754. doi: 10.1105/tpc.019166

Vernoux, T., Brunoud, G., Farcot, E., Morin, V., Van Den Daele, H., Legrand, J., et al. (2011). The auxin signalling network translates dynamic input into robust patterning at the shoot apex. Mol. Syst. Biol. 7, 508. doi: $10.1038 / \mathrm{msb} .2011 .39$

Vierstra, R. D. (2003). The ubiquitin/26S proteasome pathway, the complex last chapter in the life of many plant proteins. Trends Plant Sci. 8, 135-142. doi: 10.1016/S13601385(03)00014-1

Wagner, A. (2011). The molecular origins of evolutionary innovations. Trends Genet. 27, 397-410. doi: 10.1016/j.tig.2011.06.002

Wang, H., Nussbaum-Wagler, T., Li, B., Zhao, Q., Vigouroux, Y., Faller, M., et al. (2005). The origin of the naked grains of maize. Nature 436, 714-719. doi: 10.1038/nature03863

Wang, Q., Sajja, U., Rosloski, S., Humphrey, T., Kim, M. C., Bomblies, K., et al. (2007). HUA2 caused natural variation in shoot morphology of A. thaliana. Curr. Biol. 17, 15131519. doi: 10.1016/j.cub.2007.07.059 Wang, Y.-Q., Melzer, R., and Theissen, G. (2010). Molecular interactions of orthologues of floral homeotic proteins from the gymnosperm Gnetum gnemon provide a clue to the evolutionary origin of 'floral quartets' Plant J. 64, 177-190. doi: 10.1111/j.1365-313X.2010.04325.x

Weng, J.-K., Li, Y., Mo, H., and Chapple, C. (2012). Assembly of an evolutionarily new pathway for $\alpha$-pyrone 
biosynthesis in Arabidopsis. Science 337, 960-964. doi: 10.1126/science. 1221614

Wenkel, S., Emery, J., Hou, B.-H., Evans, M. M., and Barton, M. (2007). A feedback regulatory module formed by LITTLE ZIPPER and HD-ZIPIII genes. Plant Cell 19, 3379-3390. doi: 10.1105/tpc.107.055772

Wessinger, C. A., and Rausher, M. D. (2012). Lessons from flower colour evolution on targets of selection. J. Exp. Bot. 63, 5741-5749. doi: $10.1093 /$ jxb/ers 267

Whipple, C. J., Ciceri, P., Padilla, C. M., Ambrose, B. A., Bandong, S. L., and Schmidt, R. J. (2004). Conservation of B-class floral homeotic gene function between maize and Arabidopsis. Development 131, 6083-6091. doi: 10.1242/dev.01523

Whipple, C. J., and Schmidt, R. J. (2006). "Genetics of Grass Flower Development," in Advances in Botanical Research, eds D. E. Soltis, J. H. Leebens-Mack, P. S. Soltis, and J. A. Callow (Waltham: Academic Press), 385-424.

Winter, K.-U., Weiser, C., Kaufmann, K., Bohne, A., Kirchner, C., Kanno, A., et al. (2002). Evolution of class
B floral homeotic proteins: obligate heterodimerization originated from homodimerization. Mol. Biol. Evol. 19, 587-596. doi: 10.1093/oxfordjournals.molbev.a004118

Xi, Z., Wang, Y., Bradley, R. K., Sugumaran, M., Marx, C. J., Rest, J. S., et al. (2013). Massive mitochondrial gene transfer in a parasitic flowering plant clade. PLoS Genet. 9:e1003265. doi: 10.1371/journal. pgen. 1003265

Xing, S., Li, M., and Liu, P. (2013). Evolution of S-domain receptor-like kinases in land plants and origination of S-locus receptor kinases in Brassicaceae. BMC Evol. Biol. 13:69. doi: 10.1186/1471-2148-13-69

Yamamoto, E., Zeng, L., and Baird, W. V. (1998), $\alpha$-Tubulin missense mutations correlate with antimicrotubule drug resistance in Eleusine indica. Plant Cell 10, 297-308.

Yasumura, Y., Crumpton-Taylor, M., Fuentes, S., and Harberd, N. P. (2007). Step-by-step acquisition of the gibberellin-DELLA growthregulatory mechanism during landplant evolution. Curr. Biol. 17, 1225-1230. doi: 10.1016/j.cub.2007. 06.037
You, M. G., Liu, Y. B., Zhao, T. J., and Gai, J. Y. (1995). Effects of leaf shape on seed yield and its components in soybeans. Soyb. Genet. Newsl. 22, 66-70.

Zhang, Y., and Wang, L. (2005). The WRKY transcription factor superfamily: its origin in eukaryotes and expansion in plants. BMC Evol. Biol. 5:1. doi: 10.1186/1471-21485-1

Zhao, N., Ferrer, J. L., Ross, J., Guan, J., Yang, Y., Pichersky, E., et al. (2008). Structural, biochemical, and phylogenetic analyses suggest that indole3 -acetic acid methyltransferase is an evolutionarily ancient member of the SABATH family. Plant Physiol. 146, 455-467. doi: 10.1104/pp.107. 110049

Zhu, Y., Ellstrand, N. C., and Lu, B.-R. (2012). Sequence polymorphisms in wild, weedy, and cultivated rice suggest seed-shattering locus sh4 played a minor role in Asian rice domestication. Ecol. Evol. 2, 2106-2113. doi: 10.1002/ece3. 318

Conflict of Interest Statement: The authors declare that the research was conducted in the absence of any commercial or financial relationships that could be construed as a potential conflict of interest.

Received: 01 June 2013; paper pending published: 12 July 2013; accepted: 06 September 2013; published online: 10 October 2013.

Citation: Bartlett ME and Whipple CJ (2013) Protein change in plant evolution: tracing one thread connecting molecular and phenotypic diversity. Front. Plant Sci. 4:382. doi: 10.3389/fpls.2013. 00382

This article was submitted to Plant Evolution and Development, a section of the journal Frontiers in Plant Science.

Copyright (c) 2013 Bartlett and Whipple. This is an open-access article distributed under the terms of the Creative Commons Attribution License (CC BY).

The use, distribution or reproduction in other forums is permitted, provided the original author(s) or licensor are credited and that the original publication in this journal is cited, in accordance with accepted academic practice. No use, distribution or reproduction is permitted which does not comply with these terms. 